\title{
A Referential Analysis of Fictional Names
}

by

\author{
Dylan Hurry
}

A thesis submitted to the Faculty of Graduate and Postdoctoral Affairs in partial fulfillment of the requirements for the degree of

Master of Arts

in

Philosophy

Carleton University

Ottawa, Ontario

(C)2016

Dylan Hurry 


\begin{abstract}
Do fictional names refer to fictional characters? Realists argue they do, while anti-realists argue they do not. According to referentialism, a proper name contributes its referent to the singular proposition expressed by sentences of which the name is a constituent. Furthermore, referentialists argue that the mechanism via which a name means its bearer is best understood as a causal-historical chain of which subsequent uses of the name are parasitic on some initial use (or baptism). For the anti-realist, fictional names present a problem for referentialism as many sentences, such as "Peter Pan was created by J. M. Barrie," seem to refer and express true singular propositions. However, for realists, such sentences are congruent with a referential theory of naming. I will examine two realist accounts in detail, Meinongianism and artifactualism, and argue that artifactualism is the more likely candidate for a realist referential theory concerning fictional names.
\end{abstract}




\section{Acknowledgements}

I would like to begin by thanking my thesis supervisor, Eros Corazza, for his useful comments on various drafts of this thesis. I would also like to thank him for his continued emphasis that the "devil is in the detail" when it comes to philosophizing. Furthermore, I wish to thank him for his engaging seminars on various problems in the philosophy of language. They have made me realize that the field is where I feel most at home philosophically. Lastly, I would like to thank him for being both a mentor and a friend.

I would also like to thank my undergraduate supervisor Neb Kujundzic for introducing me to both the philosophy of language and Austrian philosophy-Brentano and Meinong in particular. The original topic of my undergraduate honours thesis was reference to the non-existent, but upon realizing the vast amount of literature required to gain an understanding of the issues, the subtleness of the debates, and the intricacies involved, I ended up writing on an entirely unrelated topic in epistemology. Thankfully, I remained interested enough in the topic that I was finally able to return to it during my MA research.

A special thanks goes out to Professor Christine Koggel and my peers from the research seminar for their helpful comments on the earliest drafts of this project. The discussion section which followed various in-class presentations allowed many unnoticed leads and/or issues to be brought to my attention.

Additionally, I would like to thank my friend Gage Bonner for his comments on various drafts of this thesis and his insightful remarks concerning the topic. It never hurts 
for a theoretical philosopher to consult a theoretical physicist!

Finally, I would like to thank my parents for their continued emotional and moral support. I wish to thank my mother, Donna Hurry, for bestowing upon me her love of books and reading, and my father, Andrew Hurry, for patiently listening as I constantly rambled on about various philosophers and philosophical problems as an undergraduate while living at home. Reading and rambling are two prerequisites for the field, and as such I am eternally grateful. 


\section{Table of Contents}

Abstract

Acknowledgements $\quad$ iii

Table of Contents $\quad$ V

1. Introduction 1

2. The Referential Theory of Naming 13

3. Fictional Names: Realist and Anti-Realist Approaches 23

4. Meinongian Referential Theory 36

5. Artifactual Referential Theory 72

6. Conclusion 86

$\begin{array}{ll}\text { Bibliography } & 87\end{array}$ 


\section{Introduction}

Do fictional names refer to fictional characters? According to the referentialist tradition, if I utter "Newton made important advancements in optics" the name "Newton' contributes the referent Newton to the proposition expressed. Furthermore, given that in the actual world Newton did make important advancements in optics, the proposition expressed is true. However, fictional names present a problem for referentialism as many sentences, such as "Peter Pan was created by J. M. Barrie," seem to refer and express true singular propositions. For realists, those who hold that fictional names refer, such sentences are congruent with a referential theory of naming. I will examine two realist accounts in detail, Meinongianism and artifactualism, and argue that artifactualism is the stronger candidate for a realist referential theory concerning fictional names.

The referential theory of naming consists mainly of two separate doctrines, one concerned with the mechanism of reference, the other with the contribution of reference. ${ }^{1}$ According to referentialism, the mechanism of reference, or the way a name relates to its bearer, is the participation of the name in a causal-historical chain of which subsequent uses of the name are parasitic on some original use. The contribution of reference is the referent into singular propositions in which the object occurs as a constituent of said propositions.

Furthermore, in the referentialist tradition, proper names are understood as devices of direct reference. Demonstratives, such as 'this' or 'that,' and indexicals, such as 'I' or 'today,' are also devices of direct reference. However, where demonstratives and

\footnotetext{
${ }^{1}$ Accordingly, I will assume that in order for a philosopher to qualify as a referentialist they need to assert a version of each of these doctrines.
} 
indexicals differ from proper names is that a demonstrative or indexical acts on context to produce content, indicating that demonstratives and indexicals possess a peculiar type of meaning referred to as character (see Kaplan 1989). Proper names, on the other hand, are context insensitive, indicating that they do not act on context to produce content, but invariantly maintain their semantic meaning independently of context-this semantic meaning being the object that they name. ${ }^{2}$

The referential theory of naming holds that sentences containing proper names express Russellian (or singular) propositions, in which the object is a constituent of said proposition. Since proper names are devices of direct reference, the referent does not enter propositions via the mediation of some tertiary content, but directly as the referent. The picture of proper names that the referentialist paints is well equipped to analyze an utterance such as "Newton made important advancements in optics." Such an utterance, the referentialist holds, expresses the singular proposition $P a$, where $a$ is the object named by 'Newton' and $P$ is the property expressed by the predicate, "made important advancements in optics." If $a$ stands in relation to $P$ as the proposition asserts, then the proposition is true and false otherwise. This Russellian proposition can, by convention, be represented in set-theoretic terms as the following ordered-pair:

(1) $<$ Newton ; having-made-important-advances-in-optics $>$

The noun phrase, in this case a proper name, refers to its referent, which occurs as a constituent of the proposition. The verb phrase, in this case a particular predicate, refers to the property, which also occurs as a constituent of the proposition.

2 The referentialist usually accounts for homonymous names, e.g. the name 'John' as a name for both John Locke and John Lockwood, by appealing to the mechanism of reference. 
Now consider the utterance "Peter Pan made important advancements in optics." Given the above analysis it is tempting to claim that such an utterance expresses the singular proposition $P b$, where $b$ stands for the object named 'Peter Pan' and $P$, again, stands for the property of having made important advancements in optics, or in set theoretic terms as:

(2) $<$ Peter Pan ; having-made-important-advances-in-optics $>$

However, many philosophers are reluctant to admit that the name 'Peter Pan' contributes the referent to the proposition expressed. Such names, they hold, are empty and devoid of semantic content.

As Braun (2005) notes, utterances that are apparently about Peter Pan are problematic for the referentialist for a number of reasons. First, we have to account for the meaningfulness of the name, as 'Peter Pan' seems to have semantic content. Second, we have to account for the meaningfulness of sentences containing the name, such as:

(3) Peter Pan first appeared in The Little White Bird

(4) Peter Pan can fly and never grows old

as these seem to be meaningful sentences. Third, we have to account for the fact (3) and (4) seem to express true propositions. Referentialists have primarily two routes through which they can answer these puzzles. If the semantic content of a name is the object named, then we either need to explain such seemings away, or postulate an object $b$ that is the semantic content of our use of the name 'Peter Pan.'

Each option of the above dilemma has been vigorously defended by numerous philosophers. Those philosophers who deny that uses of 'Peter Pan' refer to an object I 
will call anti-realists, while those who postulate an object to which 'Peter Pan' refers I will call realists. ${ }^{3}$ The following table outlines the various realist and anti-realist approaches defended:

\begin{tabular}{|c|c|}
\hline REALIST & ANTI-REALIST \\
\hline Abstract Object Theory & Descriptivism \\
Possibilism & Pretence Theory \\
Meinongianism & Mention Approach \\
\hline
\end{tabular}

Depending on the realist approach one takes, Peter Pan will either be construed as an abstract, possible, or non-existent object. Regardless of whichever realist approach one takes, the reference relation is argued to hold between 'Peter Pan' and Peter Pan. By contrast, the anti-realists try to explain away such apparent reference and deny that 'Peter Pan' refers altogether.

The anti-realist argues that fictional names such as 'Peter Pan' do not function semantically as genuine names, instead being classified as 'mock' names. Being mock names, they only purport to refer, but fail to actually do so. Since 'Peter Pan' is an empty mock name, the standard referential theory of naming does not apply - in the sense that uses of the name do not contribute a referent to the proposition expressed and Peter Pan is not the origins of the casual-historical chain. Hence, on anti-realist accounts, the challenge is to explain how although fictional names are empty, statements such as (3) and (4) both (a) have the appearance of expressing true singular propositions, and (b) are

${ }^{3}$ Different terms have been used to capture the fundamental distinction. For example, while Contessa (2009) labels the realist views the hospitable approaches and the anti-realist views the eliminativist approaches, Phillips (2000) labels them the naive approach (realism) and the standard approach (anti-realism). 
meaningful. Additionally, they need to do this all while maintaining the two main doctrines of the referential theory of naming.

Empty names can be considered as those names which are thoroughly nonreferring. An anti-realist about fictional names, then, is one who claims that in their uses they are thoroughly non-referring and therefore empty. For the referentialist, an empty name is devoid of semantic content, as the semantic content of a proper name is held to be the object which it names. As a result, an empty name for the referentialist is, by definition, devoid of semantic content. This tension, between empty names and the central tenant of referentialism, has motivated some referentialists to argue for realist positions regarding fictional names-as this would allow fictional names to have semantic content; explaining the meaningfulness of sentences containing such names and why such sentences seem to be truth-evaluable.

Realist approaches treat some occurrences of the name 'Peter Pan' as genuine cases of naming, and try to account for how such names fit into the standard referential theory of naming. This entails (a) explaining how the name fits into the causal-historical chain, and (b) determining the semantic content of such a name [if not an actual concrete object]. There is a lot of linguistic data that favours a realist approach. Consider the following - in addition to (3) and (4) above:

(5) Peter Pan is more famous than J. M. Barrie

(6) J. M. Barrie created Peter Pan

(7) Peter Pan does not grow old, but he can fly [anaphoric reference]

(8) Some characters in J. M. Barrie's stories are more famous than others 
(9) Peter Pan is not to my left

The realist has a relatively easy time in accounting for such data when compared to the anti-realist, although this does not necessarily invalidate the anti-realist position. The realist and anti-realist positions, including their respective benefits and difficulties, will be explored in greater depth in Chapter 3.

Before moving on, it is important that a number of key distinctions that have been made in the literature be examined. The first of which is the difference between objectfictional and meta-fictional uses of fictional names. Statements such as (4) and (7) are often referred to as object-fictional as they occur in the fiction and talk about fictional characters as if they were actual concrete individuals. Following Thomasson (2003), I will call those object-fictional sentences which are found within works of fiction fictionalized-sentences, while those object-fictional sentences "by readers about the content of works of fiction" internal-sentences (207). Statements such as (3) and (5) are often referred to as meta-fictional because they are about a work of fiction and say something about the actual world, outside of the fiction. Everett (2000) considers statements such as (9) to be non-fictional uses of fictional names, and claims that "nonfictional uses of empty names talk about only the real world and not about fictional or mythic worlds. The truth values of such claims depend only upon what is the case in the real world and in no way depend upon what is the case in any fictional or mythical world" (38). It seems to me as if meta-fictional uses are subsumable under non-fictional uses as both are judged true or false depending on the state of affairs in the real world. 
Regardless, the distinction remains useful as meta-fictional uses seem to be a special, and interesting, case of non-fictional ones.

The distinction between uses of fictional names is useful since a sentence containing a fictional name may seem true in one context of use and false in another. For example, as an object-fictional sentence (6) seems false because the fictional character Peter Pan was not created by J. M. Barrie in the story. As a meta-fictional sentence, however, (4) seems false as Peter Pan is a fictional character, and fictional characters are not the sort of things which age (at least, on most accounts). Furthermore, a sentence such as (7) can be either an internal or fictionalized sentence, depending on whether it occurs in discourse about the work or in the work itself.

Another important distinction which has been drawn in the literature is between types of purportedly non-referring names. There is, some claim, an important distinction to be made between fictional, mythical, and empty names (see Braun 2005, Salmon 1998). What distinguishes fictional names, such as 'Peter Pan,' from mythical names, such as 'Zeus' or 'Vulcan,' is that mythical names originally purport to name some actual concrete individual, whereas with fictional names there is typically a pretence associated with their use (Salmon, 305). On realist accounts, fictional and mythical names differ from empty names by nevertheless referring, either to some abstract, possible, or nonexistent object. As such the distinction becomes semantically essential. However, realists differ as to the extent and means by which fictional and mythical names refer. ${ }^{4}$ On the

\footnotetext{
${ }^{4}$ Although the name 'Vulcan' did not originate in what we would standardly call a mythical work, the definition of 'mythical names' offered by Salmon is broad enough to encapsulate such names.
} 
other hand, staunch anti-realists argue that fictional and/or mythical names are empty, and seek to explain away any apparent reference.

It is also important to distinguish the syntactic and grammatical category that fictional, mythical, or empty terms may belong to. For example, whereas the fictional name 'Peter Pan' seems to function syntactically as a proper noun phrase that names an individual, 'Elf' seems to function as a count noun phrase that names a kind. The mythical name 'Vulcan' seems to syntactically function like the fictional name 'Peter Pan,' whereas 'Phlogiston' seems to function as a mass noun. Although these distinctions are interesting and important, it will be those fictional names that seem to function as proper names that will be my primary focus.

Salmon (1998) argues that there is also a distinction to be drawn between the degree to which a name is non-referring - although this distinction is ultimately drawn for metaphysical rather than semantical reasons. According to Salmon, "A singular term is nonreferring (with respect to a context $c$, a time $t$, and a possible world $w$ ), in one sense, if and only if there does not exist anything to which the term refers (with respect to $c, t$, and $w) "(287)$. Salmon then goes on to distinguish between very weakly nonreferring, weakly nonreferring, and strongly nonreferring singular terms. A singular term is "very weakly nonreferring (at time $t$ ) if (at $t$ ) there has existed, or is going to exist, something to which the term refers...weakly nonreferring if there might have existed something to which the term actually refers...[and] strongly nonreferring if there could not have existed something to which the term actually refers" (287). For example, 'Socrates' is very weakly nonreferring given the current $c$, $t$, and $w$ because Socrates does not 
currently exist, but did at some time $t$. 'Dolan' (the name of a possible child had a different sperm of my father united with a different ovum of my mother) is weakly nonreferring given the current $c$, $t$, and $w$ because there might have existed something to which the term actually refers. 'Dolan-23' (the purported name of a person who existed during the quantum fluctuation preceding the big bang) is strongly nonreferring given the current $c$, $t$, and $w$ because there could not have existed something to which the term actually refers.

The extent to which we must postulate degrees of nonreferring singular terms is not only a dispute amongst the realists and anti-realists but even amongst adherents of the realist approaches themselves. The Meinongian would hold that 'Dolan' refers to a nonexistent object (and is therefore not even weakly nonreferring), whereas the possibilist would hold that 'Dolan' refers to a person in some possible world (although this isn't technically at odds with Salmon's definition of nonreferring, as it is constrained by the $c$, $t$, and $w$ ). What is interesting to note is that the degree to which a singular term is nonreferring depends upon the approach one takes. An anti-realist about fictional names may admit that 'Peter Pan' is a weakly nonreferring name whereas an abstractist will hold that since 'Peter Pan' refers to an abstract object Peter Pan is not a nonreferring name at all.

In the first section of his influential paper "Speaking of Nothing" (1974) Donnellan notes that there are three kinds of apparent reference to the nonexistent (assuming only spatiotemporal concrete particulars exist). Two of which fall under the category discourse about actuality (predicative and existential statements, which are non- 
fictional uses of fictional names) while one falls under the category discourse about fiction (fictional statements, which are object-fictional uses of fictional names). Donnellan states that:

Under "discourse about fiction" I mean to include those occasions on which it is a presupposition of the course that fictional, mythological, legendary (and so forth) persons, places, or things are under discussion. I believe, for example, that said with the right intention, the following sentences would express true propositions "The Green Hornet's car was called 'Black Beauty,” "Snow White lived with seven dwarves," and "To reach the underworld, one must first cross the River Styx." (By the "right intention" I mean that the speaker wishes to be taken as talking about fiction, mythology, or legend). At the same time I also believe it is true that neither the Green Hornet, his car, Snow White nor the River Styx exists or ever has existed. These two beliefs, however, are entirely consistent. And therein lies the puzzle: how can there be true propositions that apparently involve predicating properties of what does not exist? $(1974,7)$

Donnellan notes that "what is to be excluded from consideration here [in "Speaking of Nothing"] is an account of discourse about fiction. (This is not, of course, to say that such an account is not in the end needed.)" (5). Part of my aim is to demonstrate why Donnellan's two beliefs are "entirely consistent".

Consider next, Donnellan's description of discourse about actuality:

Discourse about actuality carries the presupposition that the speaker is talking about people, places, or things that occur in the history of our world...the puzzle 
about predicative statements, as I shall call them, in discourse about actuality with a singular expression and no referent is more subtle philosophically than the puzzle about fictional discourse. There is not the same possibility of stating something true...the problem I want to concentrate on concerns "existence" statements - those that have either the form " $S$ does not exist" or the form " $S$ exists," where " $S$ " is a singular expression. Negative existence statements, unlike predicative statements, are true when there is no referent for the singular expression. $(1974,7)$

So, Donnellan's main focus is on understanding true negative existential statements when the subject term is thoroughly non-referring, with a side focus on predicative statements in which "there is not the same possibility of stating something true." Another aim of mine is to argue that Donnellan failed to notice that not all predicative discourse about actuality involving fictional names fails to be true - in fact, in what follows, the contrary shall be argued (in some cases).

Whereas Donnellan's main concern was not discourse about fiction, but discourse about actuality, which can be demarcated into predicative discourse and existential discourse, my two main concerns are discourse about fiction and discourse about actuality involving predicative statements. Although the question of true negative existential statements still receives much attention in the literature, and the debate still largely unresolved, it will not be my prime focus.

It needs to be mentioned that surveying all of these distinctions, at least at this stage of the paper, is merely meant to indicate the intricacies involved when dealing with 
fictional names (whether one is an anti-realist or realist). Of course, the stance different philosophers take to these various issues is contingent on the particular theory they endorse or are arguing for. But I've attempted to remain, up to this point, as unbiased towards the issues as possible, and to present them in as a theoretically impartial way as the topic permits.

Before proceeding to the main body of the text, I'll outline my general plan for each chapter. In Chapter 2, I'll begin by outlining the central tenets of referentialism. I'll consider how referentialism conceives of both the mechanism and the contribution of reference, proper names understood as devices of direct reference, the causal-historical account of naming, and elaborate more on the problem of empty and fictional names for referentialism. In Chapter 3 I'll briefly survey the various realist and anti-realist approaches to fictional names, examining the general approach and difficulties of each. In Chapter 4 I'll reconstruct a Meinongian referential theory that purports to solve many of the difficulties which fictional names cause for the referential theory of naming, while in Chapter 5 I'll construct an artifactualist abstract object referential theory which does the same. I will conclude that the artifactual referential theory has many advantages over the Meinongian, and that artifactualism is a strong candidate for allowing the referentialist to treat ordinary proper names and fictional proper names uniformly. 


\section{The Referential Theory of Naming}

The core elements of a referential theory of naming are often traced back to John Stuart Mill's views in his System of Logic (1843). ${ }^{1}$ Mill presents a theory of naming according to which some names are connotative whilst others are non-connotative. Mill states that, "This is one of the most important distinctions which we shall have occasion to point out, and one of those which go deepest into the nature of language" (19). According to Mill, the distinction rests on whether or not a name implies an attribute (roughly, a property in contemporary philosophy). If a name implies an attribute, in addition to signifying its subject (or denotation), then it is connotative - connoting those properties implied by the name itself. However, some names, Mill argues, are purely non-connotative: only signifying their subject.

What does Mill mean by the doctrine that some names are connotative while others are not? Consider the term 'animal.' Although 'animal' is extensionally satisfied by many things, it is hardly proper to equate these things with the class designated by the term 'animal,' although the term denotes all members of this class. That would be to misunderstand the term. Rather, the term 'animal' implies a certain set of attributes, such that if something satisfies said conditions, then it is a member of the class. But nothing is properly named 'animal' (at least, on this usage of the term-nothing ipso facto prevents any particular thing from being named 'Animal'). 'Animal,' therefore, is both connotative and denotative, as it denotes precisely those things (or subjects, to use Mill's expression)

\footnotetext{
${ }^{1}$ It is important to note that, according to Mill, "Every proposition consists of two names; and every proposition affirms or denies one of these names, of the other" (13). His use of the term 'name' is therefore very broad, and by no means inclusively suggests proper names. It is more akin to our contemporary usage of 'noun.'
} 
which possess the implied attributes.

However, according to Mill, some names are purely denotative. His paradigmatic example are proper names: such as 'John,' 'Ottawa,' 'Frege,' etc. Mill states that, “Proper names are not connotative: they denote the individuals who are called by them; but they do not indicate or imply any attributes as belonging to those individuals," and that, "these names are simply marks used to enable those individuals to be made subjects of discourse" (20). Mill then introduces his now famous Dartmouth example to illustrate his point:

It may be said, indeed, that we must have had some reason for giving them those names rather than any others; and this is true; but the name, once given, is independent of the reason. A man may have been named John, because that was the name of his father; a town may have been named Dartmouth, because it is situated at the mouth of the Dart. But it is no part of the signification of the word John, that the father of the person so called bore the same name; nor even of the word Dartmouth, to be situated at the mouth of the Dart. If sand should choke up the mouth of the river, or an earthquake change its course, and remove it to a distance from the town, the name of the town would not necessarily be changed. That fact, therefore, can form no part of the signification of the word; for otherwise, when the fact confessedly ceased to be true, no one would any longer think of applying the name. Proper names are attached to the objects themselves, and are not dependent on the continuance of any attribute of the object. $(1843,20)$ 
This passage seems to suggest that the key semantic function of proper names is in tagging or marking an individual object for subsequent discourse. ${ }^{2}$

The main appeal of Mill's theory of proper names, at least how he presents it, is that it seems to correspond to intuitions concerning the role and usage of proper names. For example, if I ask, “Can you pass Bill” (let's say 'Bill' is the name of my favourite fork), then you know (if the illocutionary act is successful) to hand me that particular fork. In this instance, 'Bill' seems to function as a semantic tag for Bill. Normally, Bill is a shortened version of the name William, and it is commonly a name given to male humans, amongst other things. But these characteristics seem unessential to the semantic function of the name 'Bill' (as the fork example demonstrates).

Unfortunately for Mill, his theory faces a number of difficulties. Consider the following:

(1) Gustav Fechner = Dr.Mises

(2) Catherine believes that Gustav Fechner is intelligent but does not believe that

Dr.Mises is intelligent

(3) Vulcan does not exist

(4) Peter Pan never grows old

\footnotetext{
${ }^{2}$ Interpreting the extent to which Mill thinks that proper names can and do imply attributes is a matter of heated debate. In the passage just quoted, Mill seems to suggest that names can imply attributes, and at another point he states that, "When we predicate of anything its proper name ... we do not, merely by so doing, convey to the reader any information about them, except that those are their names" (22, italics mine). However, it is hard to reconcile such claims with others that he makes, such as "the only names of objects which connote nothing are proper names; and these have, strictly speaking, no signification" (21). However, for our present purposes it is only important to note that Millianism, as a theory of naming, owes its general premise, and name, from the insight Mill had that proper names are purely denotative (however inconsistent the claim may be within his own work is besides the point). For a more elaborate discussion, see Lockwood (1975) or Mendelsohn (1986).
} 
These puzzles present serious difficulties for the Millian picture of proper names. If names are purely denotative, then how can (1) be informative? How is a scenario such as (2) possible? In (3) are we saying of Vulcan that it does not exist; and if so, does this require that we postulate some non-entity named Vulcan? How do we account for the meaningfulness of a sentence such as (4) without attributing a referent to the name 'Peter Pan'?

In fact, many have thought such puzzles to be so disastrous for a Millian theory of proper names that they proposed an alternative semantic analysis of ordinary proper names altogether. As Salmon (1998) states:

Russell trumpeted his Theory of Descriptions not only for its explanation (which I believe Russell saw as the theory's principle virtue) of how we gain cognitive access to the world beyond our immediate acquaintance, but also for its ability to handle a variety of puzzles that arise on his theory that the semantic content of a singular term is solely its referent [denotation, designatum]. (278)

The mentioned puzzles Russell's theory of descriptions sought to solve are the problems mentioned above: (1) Frege's Puzzle concerning informative identity statements, such as ' $a=b$ ' when ' $a$ ' and ' $b$ ' name the same thing, (2) the more general problem of substitution in certain contexts, most notably in the ascription of propositional attitudes, (3) explaining true negative singular existential statements, and (4) determining the content and truth value for sentences involving purportedly non-referring expressions. By treating 
ordinary proper names as disguised definite descriptions Russell is able to offer solutions to each of these puzzles in a single stroke. ${ }^{3}$

However, although Russell's theory of descriptions was able to accommodate the various puzzles mentioned above, beginning in the 1950s (see Strawson 1950), and continuing through to the 1970s (see Marcus 1961, Donnellan 1966/1970, Kripke 1980, and Kaplan 1989) a number of powerful objections were made against his analysis of ordinary proper names and his theory of denoting. The alternative theory of naming developed, that of referentialism, returned to a more Millian-esque theory in which proper names are devices used to 'tag' and refer directly to individual objects.

Donnellan (1966) argues that Russell failed to distinguish between the referential and attributive use of definite descriptions. On their attributive use, definite descriptions behave mostly as Russell's analysis suggests. However, on their referential use, definite descriptions directly refer to an object so as to make it salient. For example, if we are having a discussion in the library and I utter "the woman reading Plato's Cratylus is a professor of classics" I may succeed in referring to the woman I have in mind even though I mistakingly thought she was reading Plato's Cratylus when in fact it is Plato's Sophist. On Russell's analysis, since the description attributes the wrong property to the woman it fails to denote—or, at best, denotes someone else (i.e., the woman who actually

${ }^{3}$ See Chapter 3 for a more detailed analysis of Russell's solution to the meaningfulness of sentences such as (4). Russell argues that sentences containing ordinary proper names can be analyzed to reveal their true logical structure. Under such an analysis, sentences containing proper names in natural language turn out to express general propositions containing no individual whatsoever. Such an analysis is epistemically driven by Russell's key distinction between knowledge by acquaintance and knowledge by description. This distinction causes Russell, at certain points in his career, to regard demonstratives such as 'this' or 'that' as the only logically proper names. 
is reading Plato's Cratylus and is a professor of classics). Donnellan's analysis of definite descriptions as devices of direct reference easily applies to ordinary proper names, revealing proper names to function as Russellian 'genuine names' (see Donnellan 1970, 1974).

Likewise, Kripke (1980), building off the pioneering work in modal logic of Barcan-Marcus, famously argues against Russell's analysis of ordinary proper names as disguised definite descriptions. Although Kripke presents a number of arguments, perhaps the most influential has been his modal argument. ${ }^{4}$ According to the modal argument, proper names have different modal profiles than definite descriptions, and this indicates that they cannot be semantically synonymous. Consider the following:

(5) In the winter of 1917-1918, Russell gave his lectures on logical atomism

(6) In the winter of 1917-1918, the author of The Principles of Mathematics gave

his lectures on logical atomism

Whereas (5) contains the name 'Russell,' (6) contains a definite description true of Russell in the actual world. However, consider the possible world in which Whitehead, and not Russell, authored The Principles of Mathematics. In that world, the definite description "the author of The Principles of Mathematics" would denote Whitehead, not Russell. However, even in that world 'Russell' would refer to Russell (so long as Russell the object exists) and not Whitehead, for proper names are rigid designators, or so Kripke argues.

\footnotetext{
${ }^{4}$ Although Kripke also constructs an epistemic and a semantic argument against descriptivism, for sake of brevity I will only discuss the modal argument.
} 
Kripke states that, "One of the intuitive theses I will maintain in these talks [Naming and Necessity] is that names are rigid designators" (48). Something is a rigid designator if it designates the same object in all possible worlds. Since "the author of The Principles of Mathematics" behaves differently in a modal context than 'Russell,' so Kripke argues, then it is a mistake to consider ordinary proper names as disguised definite descriptions. $^{5}$

These arguments by Donnellan and Kripke, along with others, led to a decline in Russellian semantics and a resurgence of Millian semantics. Referentialists consider proper names to be devices of direct reference, referring without the mediation of a Fregean Sinn or a Russellian description (see Kaplan, 1989). This is similar to the Millian idea that proper names are purely denotative. As Thomasson (1999) notes, "Dominant theories of the reference of names have emphasized that names, unlike descriptions, function by means of a direct reference to their objects, and that causal and historical circumstances play an essential role in our ability to refer to objects by name" (43). Such devices, following Kripke, are rigid designators, designating the same object in all possible worlds. However, as Marti (1995) points out, referentialists do not always clearly distinguish the mechanism from the contribution of reference regarding names. I will now elaborate on the importance of the distinction and then examine how each raise a different set of problems for the referentialist to contend with.

\footnotetext{
${ }^{5}$ In addition to being modally rigid, Dummett (1973) has argued that they are temporally rigid as well.
} 
Questions pertaining to the mechanism of reference are chiefly concerned with one issue: what is the mechanism by means of which names refer? The question can also be rephrased as how do names have semantic content? On a Russellian analysis, ordinary proper names are disguised definite descriptions. These descriptions (purport to) uniquely apply to an individual, and whichever individual meets the conditions set forth by the description is the individual denoted by the name. That being said, on a referential analysis, names refer by belonging to a causal-historical chain. ${ }^{6}$ For example, my use of the name 'Russell' is parasitic on other uses of the same name. I probably originally heard the name in a philosophy lecture, or perhaps read it online or in a book. What is important is that if we could (with the help on an omniscient observer) 'trace' the various uses and parasitic instances of the name, the referentialist argues, we would eventually be led back to Russell himself — or the event in which someone intended to name Russell 'Russell,' most likely his parents. This originally naming, or 'baptism,' is the source of all other parasitic uses of the name 'Russell,' and the origins as to how 'Russell' refers to Russell. On this account the mechanism of reference concerning proper names is the chain of parasitic uses of the name itself. My current use of 'Russell' means Russell because of the existence of such a chain. ${ }^{7}$

${ }^{6}$ On Kripke's 'picture,' the process is causal, whereas Donnellan prefers the title "historical explanation theory." Donnellan (1974) wants to "avoid a seeming commitment to all the links in the referential chain being causal." Therefore, although today the theory is general referred to as the 'causal-historical theory' it is somewhat misleading to think of it as a unified theory accepted by all referentialists. As will become apparent, Donnellan's suggestion that we relax the causal criterion is essential to resolving the no-reference problem.

${ }^{7}$ It should be noted that Geach (1969) seems to be the first to suggest the 'chain of reference' model of naming. 
Now consider the contribution of reference involving proper names. According to the referentialist tradition, proper names contribute to propositions the object they name to form a singular proposition. On Perry's account (2012), propositions can be understood as "abstract objects that encode the truth-conditions or other relevant satisfaction conditions of utterances" (utterances being concrete sentences in context) (31). Singular propositions are "propositions with respect to which we can speak of an object or objects as constituents" (31). Therefore, an utterance of "Newton made important advancements in optics" expresses the singular proposition $P a$, where $P$ is the property having made important advancements in optics, and $a$ is the object Newton referred to by 'Newton.' This is the contribution of reference involving proper names.

Now that the contribution of reference has been clearly distinguished from the mechanism of reference (involving proper names), let us now consider some difficulties such a theory faces. The two most perennial problems for a referentialist theory of naming are the no-reference and co-reference problems, which were also problems for Mill's theory. On the referentialist view of the contribution of reference, 'Dr.Mises' and 'Gustav Fechner' contribute the same referent to propositions, so how can we explain the difference in cognitive significance in scenarios such as those outlined in (2) above involving proposition attitude ascriptions? This is the problem of co-reference. However, the no-reference problem is equally, if not more so, problematic for the referentialist. If 'Peter Pan' is an empty, or thoroughly non-referring, name, then (a) what do uses of the name contribute to sentences in which it is found, since the referent cannot enter into the 
proposition, and (b) how do we explain the meaningfulness of sentences containing the name if it does not fit into the causal-historical account of the mechanism of reference?

The referentialist has two approaches available to respond to the no-reference concerning fictional names problem. She can either admit that they are empty and (a) find a way to account for the meaningfulness, and truth-conditional behaviour, of sentences involving empty names, or (b) deny that (at least some) empty names are thoroughly nonreferring. In the introduction, (a) was dubbed the anti-realist approach while (b) the realist. In the next chapter, I will examine the dispute between realists and anti-realists in greater depth, and argue that two approaches are particularly promising for resolving the no-reference problem for referentialism: Meinongianism and artifactualism. In Chapter 4 I will examine the extent to which Zalta's Meinongianism solves the no-reference dilemma while in Chapter 5 I will examine how Thomasson's abstractist approach does. 


\section{Fictional Names: Realist and Anti-Realist Approaches}

At the end of Chapter 2 we saw that the referentialist can attempt to explain the meaningfulness and pre-theoretic truth conditions of sentences such as:

(1) Peter Pan never grows old

(2) J. M. Barrie created Peter Pan

by adopting either a realist or anti-realist stance towards purportedly empty names. According to the realist stance, 'Peter Pan' is not always thoroughly non-referring, as it refers to either a possible, abstract, or non-existent object. As such, there is no reason why sentences such as (1) or (2) are particularly problematic for the referentialist, as the semantic content of the same is still the referent. On the other hand, the anti-realist argues that such sentences only appear to refer but fail to actually do so. Anti-realists try to explain such apparent reference by adopting one of a number of strategies.

Realists and anti-realists both adhere to similar methodological constraints to support their theory. These include (a) theoretical simplicity, (b) accommodating pretheoretic intuitions, (c) logical consistency, and (d) explanatory power (see Phillips 2000). However, most realists emphasize (b) and (d) in favour of their theory, while most anti-realists appeal to (a).

The main appeal of a realist approach is that it enables us to semantically analyze sentences based on their face value rather than on some hidden logical structure or paraphrased equivalent. However, this comes at a cost. Because the realist argues that names such as 'Peter Pan' are not thoroughly non-referring, the burden is to determine 
what such names are referring to. This turns an initially linguistic question into an ontological one. If 'Peter Pan' refers, what sort of object or entity does it refer to?

The anti-realist is faced with the converse difficulty. Whereas the realist approach generally allows us to take meaningful sentences containing proper names at face value, the anti-realist has to explain how such sentences are only seemingly referential. That is, they have to explain why occurrences of 'Peter Pan' in statements such as (1) or (2) only appear, but fail, to refer. The upside of this approach is that we need not venture into any explicitly ontological territory. Many anti-realists see this approach as being more ontologically parsimonious than the realist approach, and think that the semantic burden of denying sentences containing empty names their face value is less appalling than the ontological burden of needlessly postulating entities.

However, besides these surface similarities shared by realists and anti-realists, the specific ways in which realists and anti-realists have defended their respective positions are as varied. I will briefly consider the main realist and anti-realist approaches, the reasons in favour of each approach, and the problems associated with each approach.

The first anti-realist approach I will examine is descriptivism. ${ }^{1}$ According to the descriptivist approach (see Russell 1905/1919 and Quine 1948/1962), sentences such as (1) and (2) only have the grammatical appearance of being singular expressions. That is, whereas occurrences of 'Peter Pan' in subject position seems to entail that sentences

\footnotetext{
${ }^{1}$ Alternatively, this approach can be called the 'predicate' (see Contessa 2009) or paraphrase approach. The general idea is that sentences such as (1) only appear to contain a referring singular expression, but really can be paraphrased such that no such singular expression remains (on Quine's [1962] approach, by eliminating proper names and replacing them with predicative versions of themselves).
} 
containing the name are about or refer to Peter Pan, this is merely an unfortunate and misleading consequence of what is grammatically suggested by such sentences. The hidden or logical form of a sentence such as (1) could be analyzed as:

(3) $\exists x(P x \wedge \forall y(P y \supset x=y) \wedge \neg G x)$

which, when translated into natural language, reads as (on Quine's formulation):

(4) There is an $x$ such that $x$ has the property of Peter Paning, there is at most one such $x$, and it is not the case that $x$ has the property of growing old or (on Russell's formulation):

(5) There is an $x$ such that $x$ has the property of being the male protagonist in $J$. M. Barrie's Peter and Wendy, there is at most one such $x$, and it is not the case that $x$ has the property growing old The benefit of this analysis is that the grammatically singular expression is revealed to be a general quantificational expression. The purportedly referring term in subject position is analyzed away. Therefore, the meaningfulness of a sentence such as (1) can be captured in a sentence or description such as (4) or (5).

This approach, however, faces a number of difficulties. One of the most well known being that such an analysis leads us to assign the intuitively wrong truth values to sentences such as (1). Whereas most of us (I would assume) would consider (1) to express a true proposition, the descriptivist analysis of (1) into (4) or (5) suggests that (1) expresses a false proposition-since on this account "there is no such $x$ such that" is true. The overall description is not extensionally satisfied by any particular $x$, for that would be to assume a realist rather than anti-realist stance, and as such the descriptivist paradigm 
fails to assign the correct truth conditions to sentences containing purportedly empty names.

Additionally, as Contessa (2009) notes, the descriptivist approach (particularly on Quine's formulation) merely relegates the problem of empty names to the problem of empty predicates, as nothing extensionally satisfies the property of Peter Panning (250).

Given that many metaphysicians have a difficult time accepting non-instantiated properties, the descriptivist approach is solving one difficulty by creating another one.

For our purposes, however, there is a major problem with the descriptivist approach: it is hard to see how this approach reconciles fictional names for the referentialist. Descriptivism is often seen as a competing, rather than complementary, semantic paradigm concerning ordinary proper names, and, as such, even if the descriptivist effort to eliminate ordinary proper names turns out to be successful, this is a bigger problem for the referentialist than even the no-reference problem.

The second anti-realist approach I will consider is the pretence approach. According to such an approach, sentences such as (1) are uttered with the pretence that they refer. That is, in uttering (1) the speaker doesn't mean to convey that it is really the case that Peter Pan never grows old, but that it is pretended that Peter Pan never grows old. Such an approach can ultimately be traced back to the writings of Frege, but is explicitly formulated by Evans (1982) and Walton (1990). Evan's suggests that in uttering a sentence such as (1) we are merely participating in a game of "make-believe" (364). As Thomasson (1999) states, "Walton understands sentences occurring in the context of talking about the story as claims about what kinds of pretence are appropriately engaged 
in discussing the story" (97). On this account, in uttering (1) one really means something along the lines of:

(6) The Little White Bird is such that one who engages in pretence of kind K [claiming that "Peter Pan never grows old"] in a game authorized for it makes it fictional of himself in that game that he speaks truly. ${ }^{2}$

This account explains why sentences such as (1) seem to (a) refer to Peter Pan, and (b) seem true while nevertheless failing to refer and actually (outside of the pretence) being false (as there is no such thing as Peter Pan).

However, whereas the pretence approach seems to explain the meaningfulness and truth-conditions associated with object-fictional sentences such as (1), the approach breaks down in handling meta-fictional sentences such as (2). As Thomasson (1999) argues:

The point of such remarks [remarks such as (2)] seems precisely to step outside of the game of make-believe, outside of the fictional world of the story, to say how things are from the real-world point of view... so those who do without fictional objects seem to encounter formidable difficulties in analyzing real predications about fictional objects. (98-99)

In uttering (2) I do not seem to be participating in a game of make believe, but seem to be claiming that Peter Pan, as a fictional character, really was created by J. M. Barrie. Furthermore, consider the following:

\footnotetext{
${ }^{2}$ This example is a modified version of one found in Walton (1990, p.400).
} 
(7) Peter Pan is a fictional character

The problem of a sentence such as (7) for the pretence account is that, in the story, (7) is false. Peter Pan is not a fictional character. But, in the real world Peter Pan is a fictional character, and statements such as (2) and (7) seem to be true from the perspective of the real world. Pretence theorists have a difficult time in accommodating our intuitions concerning sentences such as (7).

Whereas the descriptivist paraphrases empty names out of sentences containing them, and the pretence theorist argues that sentences containing empty names are uttered in a pretence of make-believe, the mention theorist argues that such appearances of empty names are not genuine cases of using such names but only of mentioning them. A statement such as (1) could be analyzed as such:

(8) Someone wrote a story containing "Peter Pan never grows old" (or containing sentences implying this) ${ }^{3}$

or

(9) There is an individual $x$, a naming convention $C$, and a naming network $N$, such that utterances of "Peter Pan" exploit convention $C, N$ supports $C, x$ is the origin of $N$, and $x$ never grows old. ${ }^{4}$

3 This is a modified version of the example given in Contessa (2009)-himself having borrowed this formulation of the paraphrase schema from Crittenden (1991).

4 This example is based on Perry (2012, 44). Perry (2001/2012) offers a sophisticated metalinguistic account of empty names based on Donnellan's notion of a 'block.' However, metalinguistic theories all share the difficultly of accounting for when we seem to actually use the name. Perry's account utilizes his reflexive-referential theory of naming - a view that holds single utterances can express multiple propositions. To see how many of the tenants of Perry's reflexivereferentialism can also be found in Frege, see Corazza, Hurry, and Rafferty (2016). 
Such an approach goes metalinguistic, that is, in uttering (1) we are not really using the name Peter Pan, but are only mentioning it.

However, the mention account seems to disregard instances in which purportedly empty names are actually used. The following passage is from Kripke's lectures Reference and Existence (2013), and represents one of the clearest refutations of the mention approach:

Nevertheless, this kind of metalinguistic analysis, like any other, seems to be beset by difficulties. Suppose one runs across either the name 'Vulcan' or the name 'Santa Claus.' One is an anthropologist, and one sees the name 'Vulcan' or 'Santa Claus' on a printed page, and one asks 'Is that a name?' Someone might answer, 'No, that name has no referent.' This is quite different from what one is telling the child, who is now getting grown up, when one says 'Look, Santa Claus doesn't really exist.' If one is able to tell the child that, the child must have learned something about Santa Claus. He isn't really just being told that some name, which he may otherwise not understand at all, has no referent, nor even that in a particular use it has no referent. If he comes to believe that Santa Claus does not exist, and expresses this belief afterwards by saying 'Santa Claus does not exist,' he is using the name and not mentioning it. (153)

To correlate Kripke's example to our own, occurrences of the name 'Peter Pan' in sentences such as (1) and (2) really do seem to use the name. Furthermore, the mention account has difficulties explaining sentences such as (2), which more directly seem to use rather than mention the name-there seems to be a strong sense in which an utterance of 
(2) asserts that Barrie created the fictional character Peter Pan, and not merely just the name 'Peter Pan.'

Whereas the anti-realist approaches have difficulty in accounting for both the adequate truth conditions and meaningfulness of sentences such as (1) and (2), the realists solve such difficulties by arguing that some uses of purportedly empty names are referential. The Meinongian argues that occurrences of 'Peter Pan' refer to the nonexistent object Peter Pan, the abstract object theorist argues that they refer (in some contexts of use) to the actual abstract object Peter Pan, and the possibilist argues that they refer to some merely possible concrete individual.

The most problematic of these realist approaches is the possibilist account. According to the possibilist, although the anti-realist is correct in suggesting that 'Peter Pan' does not refer to any actual concrete object, they nevertheless fail to recognize that it refers to some possible concrete object, existing in some possible world. On this approach, there is some possible individual who might have done all of the things attributed to Peter Pan in J. M. Barrie's stories, and, as such, this individual would have been Peter Pan if only it had been actual. Therefore, although there exists no actual concrete object referred to by the name 'Peter Pan,' there is a possible world in which the name succeeds in referring to Peter Pan.

Although such an approach has an amount of initial appeal to it, it faces serious difficulties, especially considering the arguments Kripke (1980/2013) has levelled against it. Let's presume someone comes across a person meeting all of the descriptions of Peter Pan on some remote and yet undiscovered island. Kripke argues that uses of the name 
'Peter Pan' in sentences such as (1) and (2) would not refer to this individual (unless, somehow, we had been mistaken all along in thinking that J. M. Barrie was concerned with writing fictional stories, and instead was actually just reporting fact). The reason being, Kripke suggests, is that a metaphysical point is being mistaken for an epistemological one. Just because it turns out that some individual in fact meets the descriptions of Peter Pan in J. M. Barrie's stories, it does not follow that our, nor Barrie's, uses of the name refer to this individual, and we were just ignorant of the fact that name actually refers to some individual.

Additionally, such an account has trouble in accounting for meta-fictional sentences such as (2). It does not seem to be the case that, in the possible world in which Peter Pan does exist, that he was created by J. M. Barrie. As Thomasson (1999) says, the possibilist view "gives us no way of accounting for the created status of fictional characters" (18). Perhaps even more problematically, since Peter Pan is indeterminate with respect to certain properties in the stories of J. M. Barrie, such as having one leg slightly shorter than the other, what of the possible worlds in which the possible Peter Pan is completely determinate with respect to every property? Which possible world does the Peter Pan of Barrie's stories reside, and how are we to determine the correct one? ${ }^{5}$

The other two realist approaches fare better than the possibilist approach. According to the abstractist approach, Peter Pan is an actual abstract object and some uses of the name 'Peter Pan' refer to this abstract object. The abstractist approach has its contemporary origins in the works of Kripke (1980/2013) and van Inwagen (1977), but

\footnotetext{
${ }^{5}$ See Contessa (2009) and Thomasson (1999) for a more thorough analysis of arguments against
} the possibilist approach. 
has received its most thorough, and I believe consistent, exposition in Thomasson's Fiction and Metaphysics (1999). On this account, fictional characters are dependent abstract artifacts, coming into and going out of existence as the concrete contingents on which they depend, such as people and literary works, come into and go out of existence.

As we shall see in detail (Chapter 5), the abstractist can easily account for metafictional statements such as (2). In such statements, the speaker is correctly asserting that Peter Pan, a fictional character, was created by J. M. Barrie. ${ }^{6}$ In meta-fictional uses, the name refers to the abstract object by its participation in the causal-historical chain (albeit a more relaxed conception of such a chain). Such an account is entirely consistent with the referential theory of naming, and as such it has been advocated by a number of referentialists (see Kripke 2013, Zalta 1988/2004, Thomasson 1999, Salmon 1998, and Braun 2005).

However, there is much debate as to how the abstract object theorist can account for the truth value of object-fictional sentences such as (1), since on most abstractist accounts, uses of the name 'Peter Pan' in such statements fail to refer. Salmon (1998) and Thomasson (1999) each suggest, in slightly different ways, that a pretence is involved in the analysis of object fictional sentences such as (1). On Salmon's account, 'Peter Pan' in (1) still refers to the abstract object, but abstract objects are not the sort of thing which grow old or not old, and (1) is therefore false. Although we pretend that it is true in the story. On Thomasson's account, object fictional uses occur in a fictional context, and in fictional contexts a pretence is involved rendering sentences such as (1) true according to

\footnotetext{
${ }^{6}$ Although abstractists disagree as to when uses of the name begin to refer to the abstract object (see Chapter 5).
} 
the story. Such accounts differ from anti-realist pretence accounts by nevertheless maintaining that, in some contexts of use, the name actually succeeds in referring (it is important to note, though, that on Salmon's analysis the name refers in both instances). ${ }^{7}$

However, two issues in particular seem problematic for the abstract object theorist. First, true negative singular existential statements with a fictional name in argument position are particularly troublesome for the abstract object theorist-e.g. "Peter Pan does not exist" (see Everett 2007). Second, does permitting referents for fictional names not lead to an unnecessarily bloated ontology? Replies to these objections will be considered in Chapter 5 .

The last of the realist approaches to be examined here is the Meinongian approach. ${ }^{8}$ Meinongianism is named after Alexius Meinong. Meinong famously defends the notion that there are some things which do not exist. Meinong's student, Ernst Mally, had perhaps a greater influence than Meinong himself on the resurgence of a Meinongian ontology and semantics in the late 1960s through to the 1980s. Philosophers such as Routley, Parsons, Rapaport, Zalta, and Castañeda have done much to bring many of Meinong's and Mally's ideas back into contemporary circulation.

The Meinongian argues that names such as 'Peter Pan' do not refer to any existing object, but instead refer to a non-existent object. ${ }^{9}$ Their argument is generally built on the

\footnotetext{
${ }^{7}$ Thomasson (1999) seems to agree with Salmon that the name refers in both instances. However, by Thomasson (2003) her view seems to have partially changed.

8 The essential doctrines for a theory to be labelled as 'Meinongian' seem to be (1) Some things do not exist, and (2) Non existent objects possess the properties they are characterized as having.

${ }^{9}$ Routley (1979) prefers to label this relation aboutness, since he thinks that refers is too ontologically committing. However, most other Meinongian's continue to use refers.
} 
premise that 'there are' and 'there exist' are not equivalent phrases. Whereas both are standardly translated unambiguously into quantificational logic as:

(10) $\exists \mathrm{x}$

the Meinongian thinks they should be semantically distinguished, such that 'there are' and 'there exist' are represented (respectively) as:

(11) $\exists \mathrm{x}$

(12) $\mathrm{E} ! \mathrm{x}$

However, in order for 'there exists' to be properly analyzed as (12), the RussellianFregean analysis of existence as a second-order predicate needs to be rejected. ${ }^{10}$

Such an approach accounts for the no-reference problem by admitting that there are referents for empty names, however, these referents do not exist. A number of arguments were raised against Meinong's naive object theory to show that it is inconsistent (see Chapter 4), but various neo-Meinongian approaches have been able to establish consistent Meinongian theories which offer both individuating and identity conditions for non-existent objects. In statements such as (1), the speaker is correctly attributing the property of never growing old to the non-existent object Peter Pan.

However, the Meinongian approach faces a similar problem as the possibilist approach. Most Meinongian theories conceive of non-existent objects as what Voltolini (2006) has called free-idealities. That is, they are discovered rather than created. On that account, (2) would be false. However, whereas (2) is a problem for the possibilist because

\footnotetext{
${ }^{10}$ The reason is that on the Russellian-Fregean analysis 'there are' and 'there exist' are treated synonymously. If this analysis is correct, then the Meinongian dictum that some things do not exist would express the outright contradiction that there exist some things which do not exist.
} 
the possibilist conceives of Peter Pan as a possible concrete object, and concrete objects are not created by J. M. Barrie in the way (2) implies, this is not an issue for the Meinongian since Meinongianism itself establishes (2) to be a false proposition, not a problematic proposition.

Perhaps the biggest objections to the Meinongian approach are the following, (a) the need to abandon the classic reading of 'there are' and treat existence as a first-order predicate (so as to not fall into the contradiction of asserting that there exist some things which do not exist), and (b) accounting for trans-story identity when different works by the same, or different, author attribute new properties to the fictional character. The Meinongian, however, sees no problem in dealing with (a). It is (b) that raises the truly problematic question.

Now that the various anti-realist and realist approaches have been surveyed, along with the standard objections to such theories, we are ready to examine two realist approaches in greater detail: the Meinongian and the abstractist. Each has their merits, although I will argue that the abstractist prevails where the Meinongian fails. Ultimately, though, it is important to note that the Meinongians were the first to put forth a serious realist referential theory dealing with fictional objects. As such, I will proceed by examining the foundations of Zalta's neo-Meinongian approach in Chapter 4, the main problems for such a theory, and then examine the competing artifactualist approach in Chapter 5. 


\section{Meinongian Referential Theory}

Meinongianism ${ }^{1}$ is a realist stance according to which fictional characters are the referents of fictional names, e.g., 'Peter Pan' and 'Sherlock Holmes' refer to Peter Pan and Sherlock Holmes. However, unlike those who consider such referents to be either possible or abstract objects, Meinongians conceive of such referents as non-existent objects. The Meinongian, therefore, appears to offer a semantic theory for fictional names that seems entirely congruent with the referential theory of ordinary names as outlined in Chapter 2. Edward Zalta (1988/2004) has attempted to demonstrate how non-existent referents, the semantic content of fictional names, fit into the causal-historical chain. However, such a theory often seems prima facie implausible to those not familiar with the details and origins of Zalta's position, as the very notion of there being things which do not exist has seemed counterintuitive to many. Prior to examining the specific way in

1 Meinongianism is not as much a distinct philosophical school as it is an approach to philosophical problems which, in its contemporary derivations, can be traced back to the writings and thought of the Austrian philosopher Alexius Meinong (from which its title is derived). Although it is debated as to what principles a theory needs to possess in order to be considered Meinongian, in general all theories labelled 'Meinongian' share the theme of permitting nonexistents into their semantics, theories of intentionality, and metaphysical theorizing. That is, the traditional ontological/referential assumption that to think or speak of non-existent objects is logically misinformed (i.e., Russell) or metaphysically impossible (i.e., Plato) is rejected. Meinongian's can therefore be thought of as those philosophers who hold that the set of nonexistent objects is not empty or null. However, apart from this doctrine, various Meinongian's diverge quite a bit from one another as to how they develop their particular strain. It should be noted that Meinong (1904) himself seems to consider non-existent objects to be concrete particulars that possess variegated levels of being ranging from non-existence (proper) to a type of being he calls subsistence - but non-existents, whether non-existent (proper) or subsistent, are held to be metaphysically distinct from concrete existent beings such as you and I.

The way I use the term 'Meinongian,' as a realist stance towards fictional characters, should be considered a narrow usage. For our considerations, the subset of (purportedly) non-existent objects I am concerned with in this discussion is the subset of non-existents relating to fiction. This is an important distinction, as Meinongianism (in a general usage of the term) is usually concerned with the set of non-existent objects at large, so my use here is derivative and in some sense less committal. 
which Zalta establishes a reputable Meinongian referential theory, I will survey the historical background so as to make the idea that things do not exist more palatable.

The debate concerning the status of non-existent objects entered its contemporary phrase largely due to the work of Alexius Meinong. Meinong, explicating the implications of Franz Brentano's doctrine of intentionality, attempted to account for the aboutness of the mental towards non-existent objects, such as Hume's golden mountain or the infamous round-square. As we shall see, it is this doctrine of intentionality which ultimately grounds Meinong's advocacy of non-existent objects-as statements or thoughts with a non-existent object as a constituent seem to be about that object. However, Meinong's object theory (in its naive version) endorsed what has been dubbed "the freedom of association," which has been shown to lead to logical inconsistencies-a consequence which Russell thought was disastrous for Meinong's object theory.

As noted above, Meinong was influenced by Brentano's doctrine of intentionality. In his highly influential work Psychology From an Empirical Standpoint (1838) Brentano attempted to determine the characteristic that demarcates the mental from the physical, and postulates that it is intentional directedness that belongs exclusively to the mental. $\mathrm{He}$ states that, "Intentional in-existence is [a] characteristic [exclusive to] mental phenomena. No physical phenomenon exhibits anything like it. We can, therefore, define mental phenomena by saying that they are those phenomena which contain an object 
intentionally within themselves" (68). ${ }^{2}$ The mental can direct itself towards a rock (an object) in a way that a rock cannot direct itself towards anything. For example, in judging that a rock is green one can distinguish the rock from the judgement that the rock is green. In the act of judging there is something judged, in the act of loving something loved, and so on for each distinctly mental activity. ${ }^{3}$

Besides Brentano's doctrine of intentionality, Meinong's object theory was also influenced by Twardowski's distinction between an object (Gegenstand) and content (Inhalt). As Findlay notes when discussing Twardowski's theory, "we therefore require three terms, an idea (Vorstellung) as a mental act, an object which is presented to us by means of this idea, and a content which exists in our idea, and through which, as intermediary, the reference to the object takes place" (Findlay 1963, 9).

Twardowski expresses this tertiary distinction himself with the following metaphor:

If we compare the idea as an act with the act of painting, the content with the picture, and the object with the subject, a landscape, for instance, depicted on the canvas, we shall have expressed approximately the relation between the ideas act,

\footnotetext{
${ }^{2}$ What Brentano means by "intentional in-existence" is not entirely clear and many scholars have offered different interpretations. However, for our present purposes all that is important is that Brentano demarcates the mental from the physical by this Scholastic notion of intentionality. It is important to note that the doctrine of intentionality originated with the Scholastics-Brentano merely resurrected the notion and used it in novel ways.

${ }^{3}$ It is important to note that Brentano and Meinong were not the first modern philosophers to highlight the importance of the intentional relation, even towards non-existent objects. Thomas Reid, the eighteenth-century Scottish realist, claims that "that act ... we call conceiving an object ... every such act must have an object; for he that conceives must conceive something. Suppose he conceives a centaur, he may have a distinct conception of this object, though no centaur ever existed" (originally in Reid 1895, but this quote is reprinted in Routley 1979, 34). However, Reid stopped short of offering a full fledged theory of objects such as Meinong's, and did not as thoroughly investigate the intentional relation as Brentano did.
} 
its content and its object. For the painter the picture is a means by which he depicts the landscape; he wishes to represent, paint, a real or imaginary landscape, and he does this inasmuch as he paints a picture. He paints a landscape, inasmuch as he prepares, paints, a picture of this landscape. The landscape is the 'primary' object of his painting activity, the picture the 'secondary' object. The case of an idea is similar. The thinking subject has an idea of some object, e.g., a horse. In having this idea, he sets a mental content before his mind. The content is an image of the horse in much the same way as the picture is an image of the landscape. If the thinker has an idea of an object, he has at the same time an idea of a content which refers itself to that object. The object of the idea as an act is its primary object; the content through which we have an idea of the object is the secondary object of the idea as act. $(9)^{4}$

In this unfortunately convoluted passage, Twardowski presents an epistemological theory of how our thoughts stand in relation to real objects. Twardowski (like Meinong) considers as real "that which is capable of concrete existence; a tree, a note, a state of grief, a movement,..." (13). If we have knowledge of a real object, such as a particular tree, this is only possible insofar as we have an idea which has as its content a tree, although this tree need not be real-e.g. it could be imagined. This theory introduces a secondary object as the means by which a knower can come to know a primary object.

\footnotetext{
${ }^{4}$ Originally found in Zur Lehre vom Inhalt und Gegenstand der Vorstellungen (1894, 17-18) translated passage found in Findlay $(1963,9)$. All subsequent references to Twardowski will be to translations found in Findlay's work.
} 
However unconvincing such a representationalist epistemology may sound, two of the four arguments Twardowski provides for distinguishing the content of an idea from its object are shared by Meinong-hence why an understanding of Twardowski is important for understanding the foundations of Meinong's object theory. The first is 'that the content of an idea necessarily exists as an integral part of that idea, whereas the object need not exist at all' (10). For example, although a golden mountain is not a real object (as far as we know), the idea with a golden mountain as its content has it as its object, which explains how we can have an idea about it. Therefore, according to Twardowski, regardless of whether or not an object exists it can nevertheless be an object of thought $(11)$

The second reason Twardowski offers in support of his theory, another endorsed by Meinong, is that "the content is necessarily mental, whereas the object may possess properties which no mental existent can possibly have" (11). For example, whereas a golden mountain would be an extended object composed of gold, we would scarcely claim that our idea which has a golden mountain as its content is an extended object made of gold. Hence, Twardowski reasons, we are justified in distinguishing between the content of an idea and its object.

Following Twardowski, Meinong bases his distinction between the object and the content of an idea primarily on the fact that we are able to think of objects which do not exist. However, Meinong offers a more fully developed theory of non-existent objects than either Brentano or Twardowski had before him. Meinong distinguishes between three types of non-existent objects (18). The first are those contingent objects whose non- 
existence is a matter of brute empirical fact (e.g., golden mountains). The second are objects which are necessarily non-existent, as their non-existence is guaranteed by their contradictory nature (e.g., round squares). Lastly, Meinong holds that some entities, although non-existent, subsist (bestehen) but do not exist in the same way you and I exist (as ordinary objects). Meinong would include abstract things like mathematical entities within this category of subsisting objects. ${ }^{5}$

Meinong argues that philosophers have a prejudice in favour of the actual-i.e., when philosophizing about various objects philosophers tend to be concerned only with the set of objects which exist; despite there being good reasons to embrace non-existent objects. Because of this prejudice, according to Meinong, philosophers are hesitant to even postulate non-existent objects, let alone develop a full fledged theory of objects which deals with all objects in general: existent or non-existent. Developing a full fledged theory of objects is precisely the task Meinong set upon himself, and in 1904 he published his Uber Gegenstandstheorie (or The Theory of Objects). ${ }^{6}$ This work contains the exposition of many of his thoughts concerning non-existent objects (and objects in general), and provides the foundation for his subsequent thought and much of what has become known as neo-Meinongianism.

\footnotetext{
${ }^{5}$ Meinong's trifold division of non-existing objects is controversial. It is difficult to determine if Meinong solely held this view early in his advocacy of his theory of objects, or if he came to reject it. Most neo-Meinongian theories reject the notion of subsistence, usually because of the term's opacity.

${ }^{6}$ It is perhaps useful to note that in this work Meinong distinguishes metaphysics from the theory of objects as he intends it. Metaphysics is defined by Meinong as an a posteriori empirical investigation into the objects of actuality whereas the theory of objects remains interested in all objects, whether they possess being or not. Although both are sciences of the highest generality, according to Meinong, the set of non-existent objects greatly outnumbers the set of existent ones and as such a philosophical theory concerning objects is incomplete until one can satisfactorily account for these non-existent objects as well.
} 
The central principle running through his Gegenstandstheorie is that objects are impartial to being (Sein) and non-being (Nichtsein), sometimes called the principle of independence. ${ }^{7}$ For example, whether we are thinking of the number $\pi$ (pi), President Obama, Peter Pan, or the largest prime number, we are thinking of an object-its ontological status being irrelevant to its object-hood. Although every object is impartial to being or non-being, every object has determinate characteristics (Sosein). ${ }^{8}$ These characteristics are the properties that make the object the object that it is-e.g. $\pi$ (pi) has the properties of being a transcendental number, a mathematical constant, the ratio of a circles circumference, and so on until we exhaust the properties of $\pi$ (pi).

Perhaps the following quote from Meinong (1960) will highlight what he has in mind with this principle:

... what is to be an object of knowledge does not in any way have to exist ... The fact is of sufficient importance for it to be formulated as the principle of the independence of manner of being from existence, and the domain in which this principle is valid can best be seen by reference to the circumstances that there are subject to this principle not only objects which in fact do not exist, but also such as cannot exist because they are impossible. Not only is the oft-quoted golden mountain golden but the round square too is as surely round as it is square ....

\footnotetext{
${ }^{7}$ Mally, Meinong's student, called this principle the independence of so-being (Sosein) from being (Sein) (Findlay, 44).

8 Sosein can alternatively be translated into English as 'suchness,' 'such-that,' or 'be-so.' However, I think determinate characteristics more accurately captures Meinong's intended meaning.
} 
In this passage we can find Meinong claiming the objects, whether non-existent due to what we would call brute empirical fact, or non-existent due to having a contradictory nature, nevertheless have the characteristics that make them what they are independent of whether or not they exist.

Although a number of principles can be found throughout Meinong's work, the principle of independence and Brentano's doctrine of intentionality are the most essential. However, to have an understanding of Meinong's object theory one needs to briefly consider all of the main principles. Jacquette (1996) provides us with such a list:

(1) Any thought or corresponding expression can be assumed (Principle of unrestricted free assumption)

(2) Every assumption is directed towards an intended object (Intentionality Thesis)

(3) Every intentional object has a nature, character, Sosein, 'how-it-is,' 'so-being,' or 'being thus-and-so,' regardless of its ontological status. (Independence of Sosein from Sein thesis)

(4) Being or nonbeing is not part of the Sosein of any intentional object, nor of the object considered in itself. (Indifference thesis or doctrine of the Aussersein of the homeless pure object)

(5) There are two modes of being or Sein for intentional objects:

(a) Spatio-temporal existence

(b) Platonic subsistence

(Existenz/Bestand thesis) 
(6) There are some intentional objects which do not have Sein, but neither exist nor subsist (objects of which it is true to say that there are no such objects). (9)

These principles provide the foundation for Meinong's object theory, and principles (2) through (4) continue to provide the basis of most (if not all) theories that can be labelled as neo-Meinongian.

Remember that according to principle (3), the independence of Sein from Sosein, every object has determinate characteristics, or properties. However, sometimes an object is incomplete, according to Meinong, if it is indeterminate with respect to certain characteristics - e.g. the round square is determinate with respect to being round but indeterminate with respect to being blue, whereas concrete existents are determinate with respect to every property (Findlay, 162). That being said, even if an object is incomplete it is nevertheless an object because it is determined by the characteristics it determinately has. The round square, an indeterminate object, according to principles (1) and (3), is determinate with respect to being round and being square, but indeterminate with respect to every other property.

The principle benefit of such a theory of non-existent objects is that it solves a number of otherwise perplexing problems. It offers a reasonable explanation of true negative existential statements, it seems to explain the intuition that some things (such as Santa Claus) do not exist, it provides a straightforward theory of mental intentionality, and, most importantly (for our purposes), it explains the meaningfulness of fictional names and how sentences which contain fictional names as constituents can express 
(seemingly) true or false propositions. However, in its naive form, Meinong's theory faces a number of difficulties.

Principles (1), (5), and (6) are usually avoided in most neo-Meinongian paradigms, and for good reason. Principle (5), as noted earlier, is difficult to understand and left opaque throughout Meinong's writings, and principle (6) can be inferred from principles (1) through (4). However, by far the most problematic premise is premise (1), which leads to the single greatest problem facing Meinong's object theory.

Principles (1) through (6) taken together have been referred to as Meinong's Naive Object Theory (hereafter abbreviated as NOT). NOT can be distinguished from subsequent Meinongian paradigms by its embracement of principle (1): the principle of unrestricted free assumption (hereafter FOA). Orilia defines it as such:

(FOA) Given any set of properties, there is a corresponding object with exactly those properties (55).

This principle states that for any set of properties, e.g., the set $\{P, Q, R\}$, there is a corresponding object with precisely those properties.

In his brilliantly insightful work 'On Denoting' (1905), Bertrand Russell spotted the logical inconsistency of a principle such as FOA. Russell states that Meinong's theory "regards any grammatically correct denoting phrase as standing for an object. Thus 'the present King of France,' 'the round square,' etc., are supposed to be genuine objects" (482-483). However, Russell then goes on to claim that such a theory is intolerable, as such objects "are apt to infringe the law of contradiction" (483). Although 
Russell himself does not demonstrate how, Parsons (1980) has offered a reconstruction of the argument demonstrating the infringement Russell most likely has in mind:

(1) The round square is round

(2) The round square is square

(3) $(\mathrm{x})(\mathrm{x}$ is square $\supset \neg(\mathrm{x}$ is round $)$

(4) $\neg$ (the round square is round)

(5) The round square is round \& $\neg$ (the round square is round)
Granted.

Granted.

$?$

From (2)(3)

This seems to be the argument Russell had in mind against Meinong. However, Parsons includes a '?' mark next to premise (3) as it is not entirely clear why the universal quantifier should be construed as broad enough to include the round square in its range (38). However, for our present purpose of historical exegesis, let us consider premise (3) to be given.

If premise (3) is assumed as given, then Russell effectively demonstrates that Meinong's FOA indeed violates the law of contradiction, surely an undesirable consequence. However, this is not the only argument Russell offers against Meinong's theory. He also briefly mentions the set \{existent, present King of France\}. According to FOA, there is an object corresponding to this set of properties, or in other words, an object has these properties as its Sosein. However, given that there is no existent present King of France, FOA implies that there both is and is not an existent present King of France-yet another undesirably consequence. 
These two arguments provided against Meinong's object theory by Russell, although only taking up two paragraphs in "On Denoting," effectively revealed NOT to be a fundamentally flawed theory. However, within his lifetime, Meinong, adopting revisions to his theory suggested in the work of his student Ernst Mally, broke away from NOT and offered a theory immune to Russell's objections. However, until the 1960s Meinong's modified version of NOT remained largely ignored. It is conceivable that the magnitude of Russell's influence on subsequent philosophers in the analytic tradition, the perceived success of his theory of descriptions (and its various applications), and the fact he briefly discredits Meinong's early NOT theory, proved to be enough to render 'Meinongian' a pejorative term.

Mally made important two distinctions that allow Meinong's general theory to overcome Russell's objections: (a) between two distinct kinds of properties, and (b) two distinct ways an object stands in relation to its properties. The rediscovery of these distinctions were pivotal in the re-emergence of Meinongianism in the 1970s and 1980s. Although versions of Meinongianism have been argued for that are not constructed from 
either of Mally's distinctions, I will only concern myself here with the second distinction, which was pivotal in the development of Zalta's neo-Meinongianism. ${ }^{9}$

Mally's second suggestion, that we ought to distinguish between two distinct ways an object stands in relation to its properties, forms the basis of Zalta's Meinongianism. Whereas existing objects only exemplify (roughly, instantiate) their properties and relations, non-existing objects can encode certain properties while exemplifying others. ${ }^{10}$ On this distinction, objects can encode properties without exemplifying them, such that the round-square only encodes the property of being round and the property of being square, but fails to exemplify either. The properties non-existent objects encode are central to their identity (see Zalta 1983). However, non-existing objects nevertheless still exemplify certain properties. For example, the round-square exemplifies the property of being an intentional object.

Zalta (1983/1988) constructs an axiomatic Meinongianism. Although we need not go into an in-depth recount of such a construction here, certain details are crucial in understanding the way in which he reconciles fictional names within a referentialist

9 Although Meinong himself was aware of both distinctions after Mally formulated them, he chose to only accept the former (for whatever reasons). A contemporary Meinongian theory built from the first distinction has been advocated by Terence Parsons (1980). A number of Meinongian theories have been constructed out of the second distinction (see Castañeda 1972, Rapaport 1978, Zalta 1983, and Mally 1912). However, a number of other contemporary Meinongian theories which also have the ability to overcome Russell's objections have been constructed via other methods besides those suggested by Mally. For example, Priest (2005) builds a Meinongian theory via the possible worlds apparatus, while Routley (1979) constructs a version of Meinongianism that is perhaps the truest to Meinong's original vision. However, without venturing too far astray, I believe that Zalta's version is the most consistent and plausible to date, as each other version is plagued with innumerable difficulties when compared to Zalta's formulation.

${ }^{10}$ Encoding/Exemplifying are the terms Zalta uses, whereas Mally (1912) used Determining/ Satisfying(respectively) 
paradigm. For example, in classical first order calculus, ' $x$ is $F$ ' is rendered ' $F x$ ' - in Zalta's system this is read as ' $x$ exemplifies $F$ ”. However, ' $x$ is $F$,' when the intended reading is " $x$ encodes $F$," is to be rendered as ' $x F$.' Additionally, Zalta introduces existence as primitive first-order theoretical relation, which he renders ' $E$ !.' 11 Zalta then distinguishes between ordinary individuals $(O ! x)$ and abstract individuals $(A ! x)$, and claims that " $x$ is abstract (" $A$ ! $x$ ") iff $x$ fails to exemplify existence" $(1983,12) .{ }^{12}$ He then supplies us with three principles which form "the cornerstone of the theory of abstract objects" (13):

(i) Ordinary individuals necessarily fail to encode properties:

$(\forall x)(O ! x) \supset \square \neg(\exists F) x F)$

(ii) For every condition on properties, it is necessarily the case that there is an abstract object which encodes just the properties satisfying the condition: $\square(\exists x)(A ! x \wedge(\forall F)(x F \equiv \phi))$, where $\phi$ has no free $x$ 's

(iii) Two individuals are identical if and only if one of the following conditions holds: (a) they are both ordinary individuals and they necessarily exemplify the same properties, or (b) they are both abstract individuals and they necessarily and always encode the same properties:

${ }^{11}$ Zalta (1983) notes that by exists he means "having a location in space-time" (52). The need for distinguishing existence as a primitive relation is to accurately convey the distinction Meinongian's argue exists between the English phrases 'there is' and 'there exists.' He also notes that he takes the words 'existing,' 'actual,' and 'real' as synonymous (173). On this reading, Meinongianism can be seen as a parsimonious theory regarding what exists, as only spatiotemporal things would be considered existent. However, Zalta also notes that there are at least three readings of his axiomatic system. However, Zalta, at least the Zalta of 1983, prefers the Meinongian reading given above. For our purposes this reading will suffice.

12 This is essentially why Zalta's abstract objects can be considered Meinongian objects, as they always fail to exemplify existence, and, as such, are non-existent. 


$$
(O ! x \wedge O ! y \wedge \square(\forall F)(F x \equiv F y)) \vee(A ! x \wedge A ! y \wedge \square(\forall F)(x F \equiv y F))^{13}
$$

Principle (ii) acts as an individuating condition for Meinongian objects, while (iii) acts as an identity condition for both existing and non existing objects. Armed with these principles, Zalta is able to offer a formalized response to Russell's critiques of NOT.

Remember one principle in particular caused a host of difficulties for NOT:

(FOA) Given any set of properties, there is a corresponding object with exactly those properties.

However, Zalta's encoding/exemplifying distinction allows the principle to instead be represented as:

$(\text { FOA })^{1}$ Given any set of properties, there is a corresponding abstract object which encodes exactly those properties. ${ }^{14}$

The round-square can be can defined in second-order calculus as:

$$
\text { (7) }((\exists x)(A ! x \wedge(\forall F)(x F \equiv F=R \vee F=S)))
$$

Which reads "there is an abstract object, such that it encodes (only) the property of being round and the property of being square." However, such an object does not violate the law of non-contradiction as it does not exemplify the property of being round and not round. The second example that was supposed to refute Meinongianism on logical grounds was the existent golden mountain, which on Zalta's account is represented as:

(8) $((\exists x)(A ! x \wedge(\forall F)(x F \equiv F=E ! \vee F=G \vee F=M)))$

\footnotetext{
${ }^{13}$ see Zalta $(1988,21-22)$ for his formulation of all of his Meinongian principles.

${ }^{14}$ see Zalta $(1983,12)$.
} 
Which reads, "There is an abstract object, such that it encodes (only) the property of existence, the property of being gold, and the property of being a mountain." It is by specifying the distinction between an object encoding versus exemplifying its properties that Zalta's Meinongianism is able to overcome Russell's objections.

Given Zalta's axiomatic Meinongianism, we can define fictional characters as abstract objects which encode and exemplify certain properties. For example, in an object-fictional sentence such as:

(9) Peter Pan never grows old this is represented formally in Zalta's system as:

(10) $a G$

which states that "Peter Pan encodes the property of never growing old." However, metafictional sentences such as:

(11) Peter Pan is a fictional character is represented in Zalta's system as:

(12) $\mathrm{Fa}$

which states that "Peter Pan exemplifies the property of being a fictional character." Hence, Peter Pan encodes and exemplifies different properties, depending on whether the name is used in an object-fictional or meta-fictional context.

These Meinongian objects can be taken as the referents of fictional names. Zalta (2003) holds that all significant proper names are names of objects, and that proper names name things: both existent and non-existent. Fictional names do not refer to any existing entity, but instead refer to Meinongian objects. As such, these Meinongian 
objects can function as the semantic content that gets contributed to the singular propositions expressed by utterances which contain fictional names as constituents. However, depending on the context of use, whether a meta-fictional or object-fictional use, the expressed proposition either ascribes the property to the object via the relation of encoding or the relation of exemplifying - and the truth conditions vary accordingly. For example, if one utters (9) with the intention to claim that Peter Pan exemplifies the property of never growing old, then they would utter something false.

So, Zalta's Meinongianism, as outlined so far, offers an explanation concerning the semantic content of fictional names. However, it remains to be determined how such names figure into the referentialist theory concerning the mechanism of reference: how do fictional names gain currency? Reformulated, the question is in determining how fictional names receive their semantic content, or how such names enter into the causalhistorical chain of which subsequent uses of the name are parasitic. Obviously, such objects cannot be ostensively baptized, as they are not concrete particulars, so how do they fit into the chain of reference?

Zalta (2003) notes that since fictional characters do not exist they cannot causally interact with existents. This creates a problem, namely "the problem of resolving the causal chain theory of reference with the Meinongian identification of non-causal objects as the referents of names of fictional characters" (246). Zalta then goes on to argue that the traditional notion of a baptism has been understood too narrowly, and that if we enlarge our perspective we can account for the baptism of both existents and nonexistents alike (249). The general theory he puts forth has similarities with Donnellan's 
(1974) suggestion that the causal criterion, in particular, is too restrictive. However, unlike Donnellan's theory, if the use of a name with the intention to refer ends in a socalled block this is only indicative that it does not name a concrete particular, and not no object at all.

Zalta reconciles fictional names for non-existent objects and the chain of reference by arguing that fictional characters are baptized in the very act of telling $a$ story. Rather than an ostensive pointing, the act of storytelling is an extended baptism of sorts in which the fictional name comes to refer to a Meinongian object. According to Zalta, whereas a story can be considered as "an abstract object which encodes just propositional properties and which has an author," a fictional character $x$ is a fictional character of a story $s$ "iff $x$ exemplifies some property according to $s$ " (251). For example, in writing The Little White Bird, J. M. Barrie successively baptized the fictional character Peter Pan. In telling the story, Barrie attributes a number of properties to Peter Pan, and as Barrie continues the story the baptism continues until 'Peter Pan' refers to the Meinongian object Peter Pan. In the story, Peter Pan is said to exemplify the property of never growing old, while outside such a pretence the Meinongian object merely encodes such a property. Zalta also considers fictional characters to encode the properties implied by the properties they are characterized as possessing in the story, such that by Peter Pan being characterized as never growing old it may follow that he is immune to a number of age-related diseases.

Baptisms are considered special uses of language, as speech acts through which (if successful) an object is named. Successful baptisms can be thought of as the origins of 
subsequent uses of the name to refer to the object named. Whereas ordinary objects may be baptized relatively quickly and even with only one original dubbing of the object, Meinongian objects, as they are named throughout the telling of a story, require multiple uses of the name before it begins to refer and the baptism is complete (Zalta, 250). Zalta thinks that because the baptism of a Meinongian object in works of fiction depends on the telling of the story, it is illegitimate "to ask whether or not the author is referring when he or she uses the name of a character before the storytelling is complete" (Zalta, 250).

To summarize Zalta's views concerning Meinongian objects and how they are baptized and fit into the chain of reference, consider the following quote:

In our view, if a simple sentence is meaningful, and the denotation of the names in the sentence are traced through the casual/contextual chain of reference, one will find one of two things: (a) that the first use of the name introduced or baptized an ordinary object, or (b) that the first use of the name was connected with a story of some kind, in which the name introduced or baptized a character in that story. Suppose “...D..." is an English sentence in which ' $D$ ' appears to be a name. If ' $D$ ' does not denote an ordinary object, and if no story whatsoever is connected with ' $D$,' there is no reason to think that the sentence in question is even meaningful. (Zalta 1988, 124)

It seems like a reasonable criterion for a theory of meaning to demand that a meaningful name possess either origin that Zalta suggests in the above quote. However, notice that this characterization leaves little room for truly empty names, as the divide between meaning and reference almost becomes obsolete. Zalta also states that, "the causal chain 
of reference traces back to a storytelling, and that a priori metaphysical principles, which include definitions and axioms governing the identity of stories and characters, then 'establish' or 'determine' the reference of the names involved" $(2003,252)$. These " $a$ priori metaphysical principles" include those outlined above concerning the identity and individuating principles for Meinongian objects.

Let us apply Zalta's theory to understand how fictional characters fit into the account he provides. In reading Barrie's Peter and Wendy the reader comes across the name 'Peter Pan' multiple times. The name is, on various occasions, used in differing fictional situations-e.g. as a name for someone residing in Neverland, someone who befriends Wendy, someone who defeats Captain Hook, etc. In writing this story, Barrie baptizes a Meinongian object and the reader is engaged with a name that refers to such an object. Now, if the reader then goes on to use the name in discussing the book with a friend, by saying something along the lines of, "The book is great, the most exciting part is when Peter Pan defeats his arch nemesis," the name continues on as part of a chain of reference. We could then, theoretically, trace the friends subsequent uses of the name backwards until we come across Barrie writing the stories which baptized the object. Thus, like ordinary proper names, fictional names participate in the chain of reference on which subsequent uses are parasitic on some original dubbing.

Now that Zalta's Meinongian referential theory has been reviewed, let us examine how his theory deals with the problems for a referential theory of naming as outlined in the introduction and Chapter 2. It should be relatively clear how this account purports to (a) provide Meinongian objects as the semantic content expressed by the use of fictional 
names, and (b) determine how fictional names fit into the chain of reference model in which a Meinongian object is baptized.

This theory allows the Meinongian to explain how the sentences involving a fictional name are meaningful, while also accounting for our pre-theoretic intuitions regarding the truth conditions of various sentences containing fictional names. Objectfictional sentences containing fictional names are true/false depending on whether or not the character exemplifies the properties/relations according to the story (or those properties/relations entailed by the properties/relations ascribed to the character according to the story), while meta-fictional sentences containing fictional names are true/false depending on whether or not the Meinongian object in question exemplifies the properties/relations ascribed to it in the fictional story. In either case, the standard referential theory of naming applies to fictional names as much as it does to ordinary names. Therefore, the Meinongian provides a compelling realist solution to the noreference problem.

Although Meinongian referential theory purports to solve the no-reference problem it faces a number of difficulties that question the soundness of the approach. Among these difficulties are: (a) abandoning the classic rendering of 'there exists' in first-order predicate calculus, (b) accounting for real persons in fictional contexts, (c) the identity of fictional characters across stories, (d) explaining the intuition that fictional characters are created by their authors, and (e) providing too broad of a definition of a story. I'll in turn discuss each below.

On the Meinongian reading of Zalta's theory as outlined above, 'there exists' and 
'there are' are to be sharply distinguished in their formal representation. This is necessary so as to render the Meinongian dictum that some things do not exist non-contradictory. According to the classic rendering, 'there exists,' 'there are,' 'some $x$ such that,' are all uniformly represented by the existential quantifier as:

(13) $\exists x$

Likewise, existential claims about a single individual are represented by the existential quantifier as well. The English sentence 'Socrates exists' can be represented as:

$$
\text { (14) } \exists x(x=a)
$$

which utilizes the identity relation and a name letter to say, roughly, that 'there is an $x$ such that $x$ is identical to Socrates'; or, alternatively, 'Socrates exists.' However, this rendering presumes that any name which purports to name a non-existent object is incapable of being formally represented by a constant, as existential generalization entails ontological import (Quine 1962).

My suspicions tell me that these various English phrases are represented as such in classical logic because both Frege and Russell thought that the existential quantifier was all that was needed to symbolically express whatever meaning belongs to the verb 'exists.' An examination of Frege and Russell's respective positions may prove useful in the eventual overturning of the treatment of existence as a second order predicate.

Frege's thoughts concerning existence can be found in his important, yet often overlooked, posthumously published piece, "Dialogue with Pünjer on Existence" (1979). Frege follows Kant in not treating existence as a first order predicate, but extends upon Kant's theory and treats existence as a property of properties, or a predicate of second 
order. According to Frege, to say "humans are mortal" is to predicate upon humans the property of being mortal. However, to say "there exist humans" is to not predicate upon humans the property of existence, but rather to say that there are things which extensionally satisfy the property of being human. ${ }^{15}$ On this account, existence is not applied to objects, but rather to concepts which objects can fall under. This view is the main source behind Frege's treatment of existence as a redundant concept. ${ }^{16} \mathrm{~A}$ consequence of this view is that to quantify over a bound variable is to make an ontological commitment, a point Quine later made explicit (see Quine 1948)

Mendelsohn (2005) points out that Frege's treatment of existence can be seen to parallel his treatment of identity. Frege famously questions how informative identity statements are possible. On the topic of existence, he seems to be questioning how informative existence statements are possible. This seems to be the question previous philosophers such as Hume and Kant were trying to ask — but, and uninterestingly for our purposes, perhaps this is to read them anachronistically.

Whereas Frege conceived of existence as a property of concepts, Russell (at least the Russell of 1919) thought of it as a property of propositional functions. According to Russell:

A 'propositional function,' in fact, is an expression containing one or more undetermined constituents, such that, when values are assigned to these constituents, the expressions becomes a proposition. In other words, it is a function whose values are propositions...examples of propositional functions are

\footnotetext{
15 This general line of argumentation can be found in the dialogue (54)

${ }^{16}$ To be a property, for Frege, is to be a concept instantiated by some object
} 
easy to give: ' $x$ is human' is a propositional function; so long as $x$ remains undetermined, it is neither true nor false, but when a value is assigned to $x$ it becomes a true or false proposition. (1919, 193-194)

Russell regards existence as a property of propositional functions - that is, unlike propositional functions themselves which take names as inputs and output truth values, existence is a property of propositional functions themselves (again, it is a second order treatment). Russell states that:

We may correctly say "men exist," meaning that " $x$ is a man" is sometimes true. But if we make a pseudo-syllogism: "Men exist, Socrates is a man, therefore Socrates exists," we are talking nonsense, since "Socrates" is not, like "men," merely an underdetermined argument to a given propositional function. The fallacy is closely analogous to that of the argument: "Men are numerous, Socrates is a man, therefore Socrates is numerous..."though it is correct to say "men exist," is incorrect, or rather meaningless, to ascribe existence to a given particular $x$ who happens to be a man. $(1919,205)$

Russell goes as far as to say that, "When you take any propositional function and assert of it that it is possible, that it is sometimes true, that gives you the fundamental meaning of 'existence' $(1918,195)$. On Russell's account, then, informative existence statements just are synonymous with propositional functions satisfied on the extensional levelotherwise they are redundant. 
As Salmon (2014) notes, on Russell's account when one asserts that ' $a$ exists,' where $a$ is a genuine singular term, the assertion is neither true nor false but meaningless. ${ }^{17}$ Consider the following passage from Russell:

[The] actual things that there are in the world do not exist, or, at least, that is putting it too strongly, because that is utter nonsense. To say that they do not exist is strictly nonsense, but to say that they do exist is also strictly nonsense (99). There is not an idea [of existence] that will apply to individuals. As regards the actual things there are in the world, there is nothing at all you can say about them that corresponds to this notion of existence. It is a sheer mistake to say that there is anything analogous to existence that you can say about them. You get into confusion through language, because it is a perfectly correct thing to say 'All the things in the world exist,' and it is so easy to pass from this to 'This exists because it is in the world.' There is no sort of point in a predicate which could not be conceivably false. I mean, it is perfectly clear that, if there were such a thing as this existence of individuals that we talk of, it would be absolutely impossible for it not to apply, and this is the characteristic of a mistake. $(1918,108$-italics are mine)

Existence, then, is not a property of individuals, rendering the Meinongian claim that there are some things that do not exist as utter nonsense.

\footnotetext{
${ }^{17}$ According to Russell, genuine singular terms include demonstratives such as 'this' or 'that.'
} 
Classical logic, largely informed by the insights and arguments of Frege and Russell, treats 'Socrates exists' as:

$$
\text { (15) } \exists x(x=a)
$$

which is to say, if (1) is true, that:

$$
\text { (16) } \neg \exists x(x=a)
$$

is false. If (6) is false, then there is no $x$ such that an object is identical to; or, that $a$ is an empty term, or pseudo-name. Some claim that (6) represents the notion that $a$ fails to refer. This classical treatment explains why Meinong's claim that some things do not exist seems like a blatant contradiction, as it could be represented as:

$$
\text { (17) }(\exists x) \neg(\exists y)(x=y)
$$

But Meinong could not have asserted such an obvious contradiction, could've he? To be fair, he expressed his theory in natural, rather than formal, language, which leaves his claims ambiguous and open to interpretation. The principle of charity should be applied, such that Meinong was not explicitly endorsing something like (17).

Salmon (2014) and Parsons (1979/1982) make a good case against the classical treatment of symbolically treating 'there exists' and 'some $\mathrm{x}$ such that' as equivalent. Russell famously held that the grammar of natural language is misleading and obscures the underlying logical of many of our statements. He states, "Misled by grammar, the great majority of those logicians who have dealt with this question [that of existence] have dealt with it on mistaken lines. They have regarded the grammatical form as a surer guide in analysis than, in fact, it is" (208), and that "'Scott exists' is bad grammar. It can, at best, be interpreted as meaning, 'the person named Scott exists,' but 'the person named 
Scott' is a description, not a name. Whenever a name is used properly as a name it is bad grammar to say 'that exists' $(1959,185)$.

However, Salmon and Parsons argue that Russell's anti-grammatical argument may be mistaken. Salmon (2014) claims that, "Many accounts of individual existence attributions take their cue from the famous Kantian dictum, 'Existence is not a real predicate.' ... The account I shall defend results directly from a flat denial of the dictum" (246). Salmon then points out, rightfully, that the aforementioned Kantian dictum really consists of two separate thesis:

(18) The Metaphysical Thesis: existence is not a property of individual things and,

(19) The Logical Thesis: the English verb 'exists' is not of the logical type extensional first-order monadic predicate (246)

and then claims that Russell endorsed both of these theses. Salmon not only argues against the metaphysical thesis by claiming that existence is a property that some individuals, but also against the logical thesis in asserting that the verb 'exists' is an ordinary first order monadic predicate (246). His argument for rejecting the logical thesis is that "the verb 'exist' satisfies every reasonable syntactic and pragmatic criterion for being an extensional first-order monadic predicate of English" (247). He refers to his argument as the quack-quack reply. The quack-quack reply depends on two arguments, one grammatical, the other semantic:

(20) Grammatical Argument: appending 'exists' to a singular term yields a grammatical sentence 
and,

(21) Semantic Argument: 'exists' can fill the blanks in the following schema for

Leibniz's Law: If $x=y$, then $x$ iff $y$

For example, (20) suggests that if we taken a singular term, say 'Scott,' and append the verb 'exists' then we form a grammatically correct sentence, e.g., 'Scott exists.' This seems like a reasonable criterion. (21) suggests that if Cicero is identical to Tully, then Cicero exists if and only if Tully exists. This also seems like a reasonable criterion.

Furthermore, Salmon argues, not only can 'exists' be meaningfully attributed to individuals, contrary Russell, but it is even false of particular things - such as Russell himself! Therefore, according to Salmon, sentences such as "Peter Pan exists," "Peter Pan does not exist," "it is not the case that the golden mountain exists," etc., are not logically invalid - they may be all true, all false, but they are not prima facie misguided solely due to the verb 'exists' being inadequately applied to singular terms.

Likewise, Parsons (1979) argues that "people behave differently when they fail to refer than when they refer to something that doesn't exist" (95). He suggests that the Russellian project of paraphrasing phrases such as "the unicorn I dreamed about last night looked pretty silly" so as to eliminate any apparent reference to a non-existent object has failed, as nobody has correctly identified how to produce valid paraphrases (97). This is not to suggest it is not in theory possible, but merely that it has not satisfactorily been done. Parsons then suggests that "speakers of English act as if they sometimes refer to nonexistent objects. We either have to take this at face value or 
explain it away. Nobody knows how to explain it away" (97). Parsons then suggests that we ought to try an alternative route, and take it at face value.

Parsons gets us to consider a sentence such as:

(22) Pegasus is not the chief Greek deity; Zeus is

and then states that, "I suggest that you are not only willing to assert these sentences, but you are also prepared to treat the singular terms in them as if they referred; you are willing to 'refer back' to previous utterances of 'Zeus' with pronouns, and you do not treat questions about the chief Roman deity as spurious" (97-98).

What Parsons and Salmon demonstrate is that there are good reasons to treat socalled empty terms as singular terms of which existence can be meaningfully affirmed or denied. It is not as if the classical Fregean-Russell treatment of existence as a second order predicate is in and of itself a knock down argument against Meinongian theories, revealing such theories to be blatantly inconsistent. Logics have been developed that avoid such a 'confusion,' and it should therefore seem at least conceivable that there is no formal obstacle behind a theory that deals with non-existent objects. As such, although Zalta's theory on its Meinongian reading entails that we abandon the classical rendering of 'there exists' and 'there are,' this in itself seems like illegitimate grounds for dismissing the theory.

Another argument against Zalta's Meinongian theory of fictional names is offered by Thomasson. Thomasson (1999) suggests that Zalta's theory is inadequate when it comes to handling real persons in fictional contexts. Thomasson suggests that Zalta's theory allows us to read a sentence such as: 
(23) Gottlob Frege never grows old ${ }^{18}$

in one of two ways. Thomasson holds that Zalta could first suggest that the sentence, like its truly fictional counterpart "Peter Pan never grows old," expresses the proposition that the object referred to by the name in subject position encodes the property of never growing old. However, on Zalta's theory real objects can only exemplify their properties, so this solution is untenable. The second route Zalta could take, according to Thomasson, is to paraphrase (23) such that, according to the story, Gottlob Frege never grows old. On this reading, although the real Gottlob Frege does not possess this property, he does according to the story. Thomasson then critiques this option, as "it requires that we read sentences taken in the same context, with the same surface grammar, differently solely because they are about objects of a different type" (105).

Although Thomasson's argument seems convincing, it mischaracterizes Zalta's actual position. First, although Thomasson is correct in suggesting that Zalta's Meinongianism is such that real objects never encode their properties, remember that Zalta holds that object-fictional sentences are those which claim that in the story $x$ exemplifies $P$. The Gottlob Frege that appears in the work of fiction does not encode any properties, but exemplifies properties according to the story. This suggests that Thomasson is incorrect in her proposal that Zalta has two options at all, and that only the second paraphrase option that she suggests is a real route.

However, her argument that the second option "requires that we read sentences

\footnotetext{
${ }^{18}$ Let's presume that this sentence occurs in some work of fiction, with the intention that the name 'Gottlob Frege' is not just a homonym that also happens to name Gottlob Frege, the logician, but is used in the fiction with the intention to introduce the historical Frege into the fiction.
} 
taken in the same context, with the same surface grammar, differently solely because they are about objects of a different type" mischaracterizes Zalta's position as well. Any object-fictional sentence preserves its truth value when prefixed by the operator according to the story. That is the mark of an object-fictional sentence. Zalta's theory holds that all object-fictional sentences have the form:

(24) $x$ exemplifies $P$

In a fictional context, whether $x$ refers to a Meinongian object or real person is irrelevant, as object-fictional sentences only claim that (24) is true according to the story. From a meta-fictional perspective, a Meinongian object (if the semantic content of $x$ ) only encodes the property, while the real object (if the semantic content of $x$ ) truly exemplifies $P$ iff it actually exemplifies $P$. Consider the following quote from Zalta, indicating that Zalta himself is well aware of his theory being able to handle real persons in fictional contexts (1988):

So a character of a story is any object $x$ such that there is a property $x$ exemplifies in the story. Though this definition permits real individuals to be characters of stories, we are interested in the fictional characters [in the work in which this quote appears]. Fictional characters differ from other characters by the fact that they originate in the stories. An individual $x$ originates in a story $s$ just in case: (i) $x$ is abstract, (ii) $x$ is a character of $s$, and (iii) $x$ is not a character of any story authored before $s .(125)$

Therefore, Thomasson's argument that Zalta's theory fails to account of real persons in fictional contexts seems unsatisfactory. 
That being said, Thomasson (1999) provides another argument against Zalta's Meinongianism: it seems to inadequately account for the identity of characters across stories. For example, we seem to think that the Peter Pan referred to in Barrie's The Little White Bird is the same as the Peter Pan referred to in Barrie's Peter and Wendy. Despite this intuition, Zalta's theory suggests that Meinongian objects are identified and individuated solely by the properties they encode — but then each time Barrie authors a new story, attributing new properties to Peter Pan, he refers to a new object! Even worse, Zalta's theory seems to suggest that the name 'Peter Pan' fails to refer until Barrie has finished telling the story—but does this not entail that until Barrie authors his last work containing the name 'Peter Pan' that the name fails to refer until then? It would seem as if during the time between authoring The Little White Bird and Peter and Wendy the name fails to refer to any Meinongian object whatsoever, as Barrie has yet to complete the story containing the name, and has therefore, on Zalta's account, failed to finish baptizing the object. ${ }^{19}$ This seems like an entirely unwarranted consequence, and I think it represents a major blow to Zalta's Meinongian theory of fictional characters.

Another objection is that Zalta's theory seems unable to account for meta-fictional sentences such as:

(25) Peter Pan was created by J. M. Barrie

\footnotetext{
19 This interpretation of Zalta is strongly suggested when he states that: "Hunter has apparently raised two basic problems: (i) the problem of resolving the casual chain theory of reference with the Meinongian identification of non-causal objects as the reference of fictional characters (within the context of a single story), and (ii) the problem of referring to a character developed over a series of stories while the stories are being developed. However, in this paper, we plan to focus primarily on problem (i) and leave a more detailed consideration of (ii) to some other occasion. Part of the reason for doing this is that we accept the prima facie case for thinking that (ii) may be subsumed under or reduced to (i) by regarding a series of related stories as a single, lengthy story" (see 1988, 4).
} 
which many would pre-theoretically judge to be true. The problem is that if a Meinongian agrees that (25) is true, then on a reasonable definition of 'created' the author is bringing the object Peter Pan into existence. But then it is not a non-existent Meinongian object at all, but an existent object, and the entire Meinongian story falls apart. The Meinongian, then, can either claim that our pre-theoretic intuitions concerning (25) are false, or that in what (25) really entails is that J. M. Barrie baptized the Meinongian object with the name 'Peter Pan' in authoring his stories. That is, Barrie created the name to refer to the Meinongian object Peter Pan, although he did not create the object named. However, this metalinguistic reading seems illegitimate, as that does not seem to be what we are suggesting when we think that (25) is true. Additionally, there seems to be a very real sense in which we believe that Barrie brought Peter Pan into existence, and that it is not as if some Platonic Peter Pan was discovered by Barrie.

Continuing along these lines, the Meinongian position seems even worse off when we find Zalta himself claiming that, "Fictional characters differ from other characters by the fact that they originate in the stories" (125). Zalta leaves this sentence ambiguous, but in claiming that they "originate in the stories" Zalta's position seems to leave Meinongian territory altogether and venture into an artifactualist account, the kind of position Thomasson (1999) advocates (which we will examine in the next chapter). All together, meta-fictional sentences such as (25) seem particularly problematic for a Meinongian theory of fictional characters.

Additionally, although an initial appeal of Meinongianism is its ability to account for true negative existential statements, such as "Peter Pan does not exist," it seems to do 
so in the wrong way. On metalinguistic accounts, the truth of the negative existential is dependent on whether or not the name in subject position is non-referring or not. If "Peter Pan does not exist" is judged to be true, this is because the name 'Peter Pan' is nonreferring. However, according to the Meinongian it is true because the name refers de re to the Meinongian object Peter Pan, to then correctly predicate upon it the property of not-existing. However, this account seems more complicated than the metalinguistic one, since it requires (a) a de re use of the fictional name, (b) treating existence as property individuals can have or lack, and (c) that individuals lacking the property of existence can be referred to. Although the Meinongian holds that (a) through (c) are only problematic if one has a "prejudice in favour of the actual," it does seem to be true that the Meinongian's story is vastly more complicated.

The last critique of the Meinongian theory that I will examine here is concerned with Zalta's notion of a story, and his claim that any meaningful sentence with a singular term refers to an object. Remember, Zalta (2003) defines a story as "an abstract object which encodes just propositional properties and which has an author" (251), and also that, "if ' $D$ ' does not denote an ordinary object, and if no story whatsoever is connected with ' $D$,' there is no reason to think that the sentence in question is even meaningful" (1988, 123-124). The notion of a story seems defined broadly enough such that:

(26) Bill went to the market constitutes a story. I authored (26), and there are propositional properties. More so, (26) seems meaningful, although I had no ordinary object in mind named 'Bill' when I 
authored (26). On Zalta's account, if we trace the chain of reference back we will find either a fictional object being baptized in the telling of a story or an ordinary object being baptized. Since when I authored (26) I had no ordinary object named 'Bill' in mind, and wasn't intending to baptize any ordinary object, then we would seem to have to go with the former. On this account, then, (26) constitutes the telling of a story, and 'Bill' refers to the character of this story. Although this consequence is entirely consistent with Zalta's account, that seems to be the problem. (26) seems, on most accounts, to be hardly adequate as a story, and seems like loose grounds on which to claim that in authoring (26) I baptized a Meinongian object.

Although Meinongian referential theory is able to extend a referential theory of naming to include reference to Meinongian objects, in a way that solves many of the apparent linguistic puzzles concerning fictional names, the theory seems to imply some odd consequences (as seen above). Even worse, the theory as outlined by Zalta has two interpretations: one Platonic the other Meinongian. As Zalta (2003) notes:

The 'Meinongian' interpretation of the formal theory adopted in this paper here is not essential. On this Meinongian interpretation, we (a) read the quantifier ' $\exists$ ' as 'there is,' (b) read the predicate 'E!' as 'exists,' and (c) interpret the theory as asserting that there are abstract objects, where 'abstract' means 'necessarily nonexistent'...But it is important to note that one can adopt a 'Platonic' interpretation of the formal theory, by using the Quinean reading of the quantifier. On this interpretation, we (a) read the quantifier ' $\exists$ ' as 'there exists,' (b) read the predicate ' $E$ !' as 'concrete,' and (c) interpret the theory presented here as asserting 
that there exist abstract objects, where 'abstract' means 'necessarily

nonconcrete.' (see footnote, 243) 20

The problem for Zalta is that the Platonic reading of the theory runs into many of the difficulties addressed above concerning the Meinongian reading. Even worse, the Platonic reading has difficulties in accounting for our pre-theoretic intuitions regarding negative existential statements involving fictional names, something the Meinongian reading is able to do. Furthermore, the Platonic reading seems to turn Zalta's account into an abstractist approach, but as we shall see in Chapter 5, there are good reasons to take an abstractist approach to fictional characters while nevertheless not treating them as Platonic objects.

20 Zalta himself notes that, "Today, I prefer the Quinean reading of the quantifiers and the Platonic interpretation of the theory" (2). It is important to note, however, that although the paper was published in 2003, it was written in 1984, and was published in German in 1987. Thus, it belongs with Zalta's 'Meinongian' corpus of the 80s, which included his 1983 and 1988 works. It is only in the English version published in 2003 that Zalta adds the footnote professing his newfound preference for the Platonic reading. 


\section{Artifactual Referential Theory}

Like Meinongianism, artifactualism ${ }^{1}$ is a realist stance according to which fictional characters are the referents of fictional names - e.g. 'Peter Pan' and 'Sherlock Holmes' refer to Peter Pan and Sherlock Holmes, respectively. The artifactualist joins the Meinongian in attempting to reconcile their theory with a referential theory of naming in attempt to solve the no-reference problem concerning fictional names. That being said, unlike the Meinongian, the artifactualist does not claim that fictional names refer to nonexistent objects. Instead, fictional names, on certain uses, refer to abstract artifacts which exist in the actual world. These abstract artifacts are dependent entities which come into and go out of existence, as the works and people they are dependent on come into and go out of existence. ${ }^{2}$

Before examining how the artifactual theory reconciles fictional characters understood as abstract artifacts with a referential theory of naming, it is important to outline what abstract artifacts are, and why fictional characters, if any, are likely to be objects of this sort. ${ }^{3}$ Examples of other abstract artifacts often cited include works of music, laws, stories, theories, etc. These entities are abstract because they lack a

${ }^{1}$ Artifactualism has also gone under the name 'Creationism.' However, I prefer the former as I think it more aptly signifies the attributes of the theory, and is also the version used by Thomasson.

${ }^{2}$ Although the artifactual theory has its origins in the works of Kripke (2013), Searle (1979), and van Inwagen (1979), I believe it has received its most thorough and consistent exposition in Thomasson (1999/2003). As such, it will be Thomasson's theory which will guide our discussion here. Salmon (1998) and Braun (2005) advocate a similar view, although there are important differences amongst each advocate, some of which will be discussed below.

${ }^{3}$ Thomasson (1999) suggests that we distinguish the ontological question concerning fictional characters from the metaphysical question. Whereas the metaphysical question is concerned with determining what reasons we have for postulating fictional characters as existing abstract objects, the ontological question is hypothetical: if fictional characters do exist, what sort of thing would they likely be? 
particular spatial location, and are artifacts as they are "created by the purposeful activity of humans" (Thomasson 1999, 35). However, abstract artifacts are not abstract Platonic entities which necessarily exist, but contingent beings that are dependent on other concrete spatio-temporal entities for (a) their existential origins, and (b) their continued existence. Whereas numbers, on a Platonic reading, are abstract objects which necessarily exist, and telephones are contingent concrete man-made artifacts, abstract artifacts can be found at the border of these other ontological extremes.

In order to better understand abstract artifacts, it is important to develop the important notion of dependence, as an essential characteristic of abstract artifacts is their dependent nature. Thomasson (1999) suggests that we can begin by defining the most general notion of existential dependence as: "Necessarily, if $a$ exists, then $b$ exists" (25). We can then make two important distinctions, between (a) rigid and generic dependence, and (b) constant and historical dependence (27). An object, $b$, is rigidly dependent on another, $a$, only if $a$ is a particular individual. On the other hand, an object, $b$, is generically dependent on another, $a$, only if $a$ is of a peculiar type. An object, $b$, is constantly dependent on another, $a$, iff whenever $b$ exists, $a$ exists. An object, $b$, is historically dependent on another, $a$, iff $b$ requires the existence of $a$ to come into existence, but can go on existing without the continued existence of $a .{ }^{4}$ The first distinction, between rigid and generic dependence, concerns which sort of thing another thing is dependent on, while the second distinction, between constant and historical dependence, concerns the way in which one thing is dependent on another.

\footnotetext{
${ }^{4}$ see Thomasson (1999) for a more thorough discussion of these distinctions (ch.2 and ch.3)
} 
To elaborate on the importance of these distinctions, consider a particular computer. The computer is generic-historically dependent on a place of construction for its existence, but such a place can cease to exist without the computer then also ceasing to exist. Conversely, the software on a computer is rigid-constantly dependent on the existence of the computer, as without the existence of the computer the software could not continue to exist.

So why are fictional characters likely to be abstract artifacts rather than Meinongian objects? The reason is that it seems as if fictional characters are dependent entities, requiring the existence of other things for themselves to be brought into existence and to continue existing. For example, it makes sense to say that Peter Pan is rigidly historically dependent on J. M. Barrie-i.e. without authoring his stories and plays Peter Pan would not have existed. Furthermore, it seems as if Peter Pan is generically constantly dependent on the stories and plays in which he is found-i.e. without the continued existence of the stories and plays in which Peter Pan is found (stories/plays themselves abstract objects dependent on concrete works and persons), it seems as if Peter Pan would cease to exist as well. We can generalize from examples to suggest that fictional characters are dependent on two categories of things:

(1) the creative acts of its author or authors [rigid historical dependence]

(2) on a literary work [generic constant dependence]

considering the dependencies suggested by (1) and (2), fictional characters seem like likely candidates as abstract artifacts, brought into existence by a concrete spatio-

\footnotetext{
${ }^{5}$ see Thomasson $(1999,35)$.
} 
temporal particular (or particulars) and existing so long as other concrete spatio-temporal particulars (such as people and works) continue to exist (as they are the means through which the stories and characters continue to exist).

This analysis of fictional characters as dependent abstract artifacts has many advantages over the Meinongian alternative. Whereas for the Meinongian fictional characters seem to be in some sense discovered, the artifactual analysis accounts for our intuitions concerning their created status. It is common in literary criticism to come across sentences such as, "Peter Pan was created by J. M. Barrie" or, "Out of all of Barrie's creations, Wendy is the most relatable." The artifactual analysis also presents us with an entity less ontologically bizarre than the Meinongian counterpart, as abstract artifacts come into and go out of existence just like all sorts of other more familiar entities - such as persons, computers, laws, and compositions. Furthermore, there is no need to identify them with mysterious Platonic abstracta which are regardless of whether or not the relevant works or people exist. ${ }^{6}$ It also allows for us to maintain the classical rendering of the English phrases 'there are' and 'there exist' as synonymous when represented in first-order calculus, as there is no need to postulate that some things do not exist, or at the very least fictional characters do not themselves seem to motivate such a postulation.

Now that fictional characters understood as abstract artifacts has been briefly outlined, let us consider how such objects fit into the referential theory of naming. In fact, the artifactual referential theory of naming, as developed by Thomasson, has much in

${ }^{6}$ I use 'are' and not 'exists' so as to leave this sentence open to a straightforward Platonistic interpretation or, alternatively, a Meinongian interpretation. 
common with the Meinongian referential theory, as developed by Zalta. This is not a coincidence, since Thomasson herself notes that she is familiar with Zalta's account. ${ }^{7}$ Thomasson states:

Although the [fictional] name cannot be directly causally related to its referent if the referent is a fictional character, it can be causally related to a foundation of the referent (namely the text), to which in turn the referent is connected by the relation of ontological dependence, enabling one to refer to these abstracta via their spatiotemporal foundations...the determination of the reference of names through a "baptism" and the continuation and proliferation of the use of a name via chains of communication can be applied in a modified version of fictional entities - provided we allow that not only causal relations but also relations of ontological dependence can form a path for direct reference $(1999,44) \ldots$ something counting as a baptismal ceremony can be performed by means of writing the words of the text or it can be merely recorded in the text, or (if the character is named later, for example by readers), it can remain unrecorded in the text. (47)

The parallels with Zalta's account are striking: we find an extended notion of the baptismal process, with the importance of the author telling a story again being emphasized; and an account as to how fictional names directly refer to fictional characters via their participation in a chain of reference.

7 While Thomasson was writing Fiction and Metaphysics (1999), Zalta's seminal paper "Referring to Fictional Characters" (2003) had only then been translated into German and published in 1987. It is this version of the work which Thomasson was familiar with (see Thomasson 1999, 159). 
However, besides these surface similarities their accounts differ to at least two important respects, (a) Thomasson allows, contra Zalta, that a fictional character may be baptized before the story telling is complete, and (b) a difference in the referential connection between fictional names and their referents (159). Whereas Zalta (2003) holds that "the causal chain of reference traces back to a storytelling, and that a priori metaphysical principles...then 'establish' or 'determine' the reference of the names involved" (10), Thomasson instead suggests that "it is the chains of dependence between stories and characters that enable us to refer rigidly to a fictional character via a copy of the story" (159). This account has a number of advantages over Zalta's, as (a) and (b) together allow enough flexibility so that the same character can develop across storiessomething Zalta's account has a difficult time explaining (see Chapter 4).

These are not the only important respects in which Thomasson and Zalta diverge, however. Their accounts also disagree as to in what contexts a fictional name refers. Consider the following:

(3) Peter Pan never grows old

(4) Peter Pan is a fictional character

According to Zalta's Meinongian referential theory, the name 'Peter Pan' in both instances refers to the Meinongian object Peter Pan (so long as (3) is an internal object fictional sentence). However, in an object-fictional sentence such as (3), Peter Pan exemplifies the property of never growing old according to the story, while merely encoding it otherwise. In other words, due to Zalta's a priori metaphysical principle the property plays a part in determining the identity and individuating conditions of the 
Meinongian object Peter Pan, but Pan actually encodes rather than exemplifies this property. That being said, in a meta-fictional sentence such as (4), Peter Pan exemplifies the property of being a fictional character proper-i.e. the Meinongian object Peter Pan really instantiates this property. It seems as if on a Meinongian reading meta-fictional and (internal) object-fictional sentences alike refer de re to Peter Pan, a Meinongian object (although in fictionalizing discourse the author's inscriptions of the name only refer de dicto until the stories are complete). The essential difference between internal objectfictional sentences such as (3) and external meta-fictional sentences such as (4), for the Meinongian, lies not in whether the fictional name refers de re or de dicto, but whether or not they claim of the fictional character that it encodes or exemplifies property $P$.

This brings us to an interesting debate within the artifactualist camp: do objectfictional sentences such as (3) refer to Peter Pan? This question is intimately related to other important questions concerning the foundations of fictional reference: (a) what kind of pretence is involved (if any) in object-fictional sentences, (b) do author's inscriptions of fictional names refer to fictional characters, and (c) how important is Donnellan's key semantic notion of having in mind. I will address each of these questions below.

All artifactual theorists agree that some degree of pretence is involved in objectfictional sentences, whether fictionalizing or internal, such as (3). They disagree with pure pretence theorists by arguing that, in some contexts, namely meta-fictional ones, fictional names nevertheless do refer to fictional characters without any pretence being involved. The question for the artifactualist, then, is what kind of pretence is involved in object-fictional sentences, is it a pretence of a de re or de dicto variety? The question is 
particularly poignant regarding fictionalizing sentences and the authors inscriptions of fictional names, as this ties the question to another: when do fictional names begin to refer?

Thomasson (2003) notes that (regarding fictionalizing sentences):

There are least two options: 1) The pretence in later sentences of fictional works is de re, so the fictional names here refer to fictional characters, of which the sentences of the novel pretend to assert various things...Or, 2) The pretence in these cases is de dicto, so that fictional names in these contexts do not refer back to some entity outside the scope of the pretence. $(210-211)$

Braun (2005) suggests that an author's use of the name only refer de re it she had "singular thoughts and intentions about that thing" while authoring the story (210). As a matter of fact, it may be entirely indeterminate as to whether or not the author actually had singular thoughts and intentions about that thing. The author could very well have thought, "I am going to dub this object 'Peter Pan,' and then write this story about him." In such an instance, the authors inscriptions would then seem to refer de re to the fictional object Peter Pan, and then pretend to ascribe various properties to Peter Pan within the pretence of the story. If it turns out the author had nothing in mind while writing the story, but let the character 'develop' (so to speak), then such uses of the name may only refer in a de dicto way-i.e. "there was some boy, such that he was named 'Peter Pan,' defeats Captain Hook, befriends Wendy, etc." In this situation, perhaps it is only once the 
audience has the character in mind that the fictional name refers de re to Peter Pan, the fictional character. ${ }^{8}$

Braun's view may entail that Peter Pan comes into existence once the author is able to entertain singular de re thoughts about Peter Pan. However, regardless of the exact time in which Peter Pan begins to exist, the referential theory of naming nevertheless then applies, as the name 'Peter Pan' does not refer until the abstract artifact has been baptized in the telling of the story and the chain of reference ensues. The issue of whether or not a linguistically competent individual can refer to something prior to having it in mind, or whether or not something can be named without having it in mind, remains a serious question for the foundation of semantics in general, and not just in relation to fictional names. As such, this question extends beyond the scope of this paper, but nevertheless, it demonstrates how intimately questions pertaining to fictional names tie into more fundamental questions concerning reference in general.

As Salmon (1998) notes, if we allow that in fictionalizing contexts fictional names refer de re to fictional characters then this explains why sentences such as (3) express singular propositions. The proposition expressed by (3) can, by convention, be represented as the following ordered pair:

(5) $<$ Peter Pan ; never-growing-old $>$

Salmon thinks that such propositions are false, as Peter Pan is an abstract object, not a real person, and as such does not grow old in the same way the proposition suggests. Part

${ }^{8}$ This seems similar to the view put forth by Kripke (2013), in which in fictionalizing contexts fictional names only pretend to refer, whereas in subsequent internal contexts they actually do refer. 
of the pretence involved in object-fictional sentences for the artifactualist is that we use the fictional name to refer de re to the fictional character, and then pretend it has the properties it does within the pretence of the story — with the pretence involved, (5) is true.

However, how does the referentialist account for situations in which the author really doesn't have Peter Pan in mind, and when an object-fictional sentence occurs in a fictionalizing context? (3) would then be a case of the de dicto kind, where 'Peter Pan' has yet to refer. Would the sentence then not fail in expressing a singular proposition with Peter Pan as a constituent? Braun (1993/2005) suggests that in instances such as these sentences such as (3) still express a proposition, but a proposition with an unfilled void, or a gap. He calls them gappy propositions. ${ }^{9}$ Gappy propositions contain an unfilled spot the referent of a singular term usually occupies. For example, if the author's de dicto use of 'Peter Pan' fails to refer (3) can be represented as the following ordered pair:

(6) $<\ldots$; never-growing-old $>$

which is, on Braun's reading, false. ${ }^{10}$ Therefore, on this theory, whether or not an objectfictional sentence such as (3) expresses a gappy proposition or not depends on whether or not the author had singular de re thoughts about Peter Pan while she was using the name.

By allowing certain uses of fictional names to refer to fictional characters, artifactualism is a useful addition to a standard referential theory of naming as it allows

\footnotetext{
${ }^{9}$ Many anti-realists have suggested that since fictional names are all empty, or thoroughly nonreferring, all atomic sentences containing them express gappy propositions. However, this antirealist account, as we saw above, runs into difficulties in then accounting for our pre-theoretic intuitions about the truth value of the propositions expressed by sentences containing fictional names. Corazza (2013) suggests that perhaps we should not put so much emphasis on our pretheoretic intuitions to begin with.

${ }^{10}$ Salmon (1998) also endorses the gappy proposition view for non-referring terms, but, unlike Braun, thinks the propositions expressed are neither true nor false.
} 
referentialism to avoid the no-reference problem concerning fictional names. It also does so with less disadvantages than if the referentialist instead adopted a Meinongian position. However, many are reluctant to adopt an artifactual stance as they feel as if the theory is too implausible. Thomasson (2003) claims that this feeling of implausibility usually comes from one of two sources, if not both: (a) our pre-theoretic intuitions regarding the truth conditions of negative existential statements involving fictional names, i.e., "Peter Pan does not exist," and (b) "the sense that accepting fictional characters would mean accepting bizarre and problematic entities" (Thomasson 2003, 219).

Everett (2007) argues that true negative existential statements involving fictional names present a serious problem for the artifactual theory, especially since the theory's ability to explain our pre-theoretic intuitions regarding sentences containing fictional names is usually one of its selling points. However, this was a problem for the Meinongian as well, as some claim that in saying "Peter Pan does not exist" we are not using the name to refer de re to Peter Pan, only to claim that it does not exist, but are claiming that the name 'Peter Pan' fails to refer. That being said, the problem seems to be even more problematic for the artifactualist, for is the artifactualist not claiming that fictional names do refer to existing things, such that there are no true negative existential statements involving fictional names?

Thomasson (2003) responds to such an objection by suggesting that there is a strong sense in which people also pre-theoretically judge the sentence "the fictional character Peter Pan exists" to be true, while nevertheless judging the sentence "Peter Pan 
does not exist" to be true as well. Thomasson develops an account which attempts to reconcile both intuitions, such that the artifactualist can explain why we pre-theoretically judge both to be true. She does so by suggesting that in order to fix the referent, be it a real person or fictional character, we need some "disambiguating concept of the sort of thing to be named" (216). ${ }^{11}$ In subsequent uses the "speakers' broad intentions regarding what ontological kind of object is the intended referent must play some role in determining which object, if any, is referred to by their use of a term"(215). She then suggests that we follow Donnellan by going metalinguistic, and generalizes from Donnellan's notion of a block to come up with the following:

If $\mathrm{N}$ is a proper name that has been used in predicative statements with the intention to refer to some entity of ontological kind $\mathrm{K}$, then ' $\mathrm{N}$ does not exist' is true if and only if the history of those uses does not meet the conditions for referring to an entity of kind K. (217)

The general idea is that when a speaker intends to refer to a real person, the name attaches to the referent in a particular way-i.e. concrete particulars such as persons may get dubbed by an ostensive baptism, or a demonstrative accompanied by an utterance of the name they are being baptized with. However, the speaker cannot expect that a

\footnotetext{
${ }^{11}$ Geach (1957) seems to suggest that names are somehow associated (he suggests through their senses) with the particular kind of thing named (i.e. that 'Churchill' names a kind of substance such that we can generalize to 'a man'). This analysis seems analogous to Thomasson's proposal, but rather than depending on the sense of a name, Thomasson instead suggests we appeal to the kind of thing through which the chain of reference begins.
} 
fictional name names a fictional person in the same way that a 'real' name names a real person, for different entities of a different kind are being named. ${ }^{12}$

The artifactualist, then, has a response to the accusation that their position is unable to accommodate our intuitions concerning true negative existential statements involving fictional names. What of the second objection, that accepting fictional characters into our ontologies would be to accept weird or bizarre entities? First, given that many people accept that other abstract artifacts exist, such as musical compositions and stories/plots, then how would another entity of the same kind being any more or less bizarre? Secondly, perhaps those who accept musical compositions and stories as abstract objects, but deny fictional characters, do so on the grounds that it is less parsimonious to allow more entities of the same kind into our ontology if such entities are not necessary. However, admitting fictional characters understood as abstract artifacts into our ontology solves a number of otherwise difficult problems. The opponent that permits the existence of stories and compositions but denies fictional characters has yet to demonstrate how the problems solved by admitting fictional characters can be resolved without admitting such entities. Furthermore, Thomasson argues that the existence of fictional characters is guaranteed by the existence of works of fiction, just as the existence of a pair of gloves is guaranteed by the existence of a matching right and left glove $(2003,222)$. Thomasson suggests that those who "accept the existence of works of literature, but deny the existence of fictional characters...have an artificially inflated idea of what would be required for there to be a fictional character" (222). Hence, anyone who accepts abstract

\footnotetext{
${ }^{12}$ See von Solodkoff (2014) for amendments to Thomasson's proposal which make it immune to a number of objections.
} 
objects of one sort or another seems pressed to accept fictional characters as well. Perhaps the austere nominalist is more justified in denying fictional characters, but then they need to show us how some otherwise difficult problems are circumvented. ${ }^{13}$

Artifactual referential theory offers a compelling solution to the various linguistic puzzles arising from our use of fictional names. On this account, in some contexts of use, fictional names refer to fictional characters. Most importantly, perhaps, is that they refer in a way entirely congruent with the standard referential theory of naming. Although some pretence is involved in object-fictional uses of fictional names, meta-fictional uses nevertheless are cases of genuine reference, and even in many object-fictional uses fictional names may still refer de re. Furthermore, the theory has less bizarre consequences than its Meinongian alternative, while also being able to overcome many objections that seem to go against the theory on first glance.

13 Other realist theories, such as versions of Meinongianism which conceive of Meinongian objects as concrete particulars, or a possibilist approach which conceives of fictional characters as possible concrete objects, seem more compatible with nominalism. 


\section{Conclusion}

I have argued that artifactualism is the most likely candidate for a realist referential theory concerning fictional names. Although Meinongianism is a viable alternative, it faces more difficulties and undesirable consequences than the artifactual account. The main benefit of artifactualism is that it allows us to apply the standard referential theory of naming to sentences containing fictional names. Like ordinary proper names, fictional names participate in the chain of reference of which subsequent uses of the name are parasitic on some initial use. Moreover, on an artifactual account fictional names contribute their referent to the singular proposition expressed by sentences of which they are a constituent. Unlike anti-realist alternatives, there is no need to find the appropriate paraphrase or determine how fictional names only function as 'mock' proper names. All things considered, artifactualism seems like a strong candidate by which to solve the noreference dilemma for a referential theory of naming. 


\section{Bibliography}

Braun, David. 1993. “Empty Names.” Nous 27: 4: 449-469.

—. 2005. "Empty Names, Fictional Names, Mythical Names." Nous 39: 596-631.

Brentano, Franz. 1874. Psychology from an Empirical Standpoint. Translated by Anto C. Rancurello, D. B. Terrell, Linda L. McAlister. London: Routledge.

Castañeda, Hector-Neri. 1974. "Thinking and the Structure of the World: Discours d'Ontologie." Philosophia 4.1:3-40.

Contessa, Gabrielle. 2009. "Who is Afraid of Imaginary Objects?" Russell vs. Meinong: The Legacy of "On Denoting." Edited by Nicholas Griffin and Dale Jacquette. London: Routledge: 248-265.

Corazza, Eros. 2013. "Fictional Names, Negative Existentials, and Fictional Situations." Conceptos 3.5: 67-97.

Corazza, Eros, Dylan Hurry, and Ryan Rafferty. 2016. "Frege Deconstructed vs. Perry Reconstructed." Philosophical Approaches to Proper Names. Edited by Piotr Stalmaszczyk and Luis Fernandez Moreno. Frankfurt-Heusenstamm: OntoVerlag: 107-121.

Donnellan, Keith. 1966. "Reference and Definite Descriptions." Philosophical Review, LXXV: 281-304.

—. 1970. "Proper Names and Identifying Descriptions." Synthese 21: 335-358.

—. 1974. "Speaking of Nothing." The Philosophical Review 83.1: 3-31.

Dummett, Michael. 1973. Frege: Philosophy of Language. Duckworth: Oxford.

Evans, Gareth. 1982. The Varieties of Reference. Oxford: Clarendon Press.

Everrett, Anthony. 2000. "Referentialism and Empty Names." Empty Names, Fiction, and the Puzzles of Non-Existence. Edited by Anthony Everett and Thomas Hofweber. Standford, California, CSLI: 37-60.

—. 2007. "Pretense, Existence and Fictional Objects." Philosophy and Phenomenological Research 74: 56-80. 
Findlay, J. N. 1963. Meinong's Theory of Objects. Oxford: Oxford University Press.

Frege, Gottlob.1979. "Dialogue with Punjer on Existence." Posthumous Writings. Edited by Hans Hermes, Friedrich Kambartel, and Friedrich Kaulbach. Oxford: Basil Blackwell: 53-67.

Geach, Peter. 1957. Mental Acts: Their Content and Their Objects. London: Routledge \& Kegan Paul.

—. 1969. "The Perils of Pauline." The Review of Metaphysics 23.2: 287-300.

Jaquette, Dale. 1996. Meinongian Logic: The Semantics of Existence and Nonexistence. Berlin: de Grugter.

Kaplan, David. 1989. "Demonstratives.” Themes From Kaplan. New York: Oxford University Press: 481-563.

Kripke, Saul A. 1980. Naming and Necessity. Oxford: Blackwell.

- 2013. Reference and Existence: The John Locke Lectures. Oxford: Oxford University Press.

Lockwood, John. 1975. "On Predicating Proper Naemes.” The Philosophical Review 84.4: 471-498.

Mally, Ernst. 1912. Gegendstandstheoretische Grundlagen der Logik und Logistik. Leipzig: Barth.

Marcus, Ruth Barcan. 1961. "Modalities and Intensional Languages." Synthese 13: $303-22$.

Marti, Genoveva. 1995. “The Essence of Genuine Reference.” Journal of Philosophical Logic 24: 275-89.

Mill, John Stuart. 1843. A System of Logic: Ratiocinative and Inductive. London: New Impression.

Meinong, Alexius. 1960. "On the Theory of Objects." Realism and the Background of Phenomenology. Edited Roderick Chisholm. Glencoe, Illinois: Free Press: 76-117.

Mendelsohn, Richard L. 1987. "Frege's Two Senses of 'Is'.” Notre Dame Journal of Formal Logic 28.1: 139-160. 
-. 2005. The Philosophy of Gottlob Frege. Cambridge: Cambridge University Press.

Orilia, Francesco. 2013. "Guise Theory Revisited." Humane Mente Journal of Philosophical Studies 25: 53-76.

Parsons, Terence. 1979. "Referring to Nonexistent Objects." Theory and Decision. Dordrecht: D. Reidal: 95-110.

—. 1980. Nonexistent Objects. New Haven: Yale University Press.

—. 1982. "Are there Non-Existent Objects?" American Philosophical Quarterly 19.4: 365.

Perry, John. 2001. Reference and Reflexivity. Standford, California: CSLI.

—. 2012. "Donnellan's Blocks." Having in Mind: The Philosophy of Keith Donnellan. New York: Oxford University Press: 30-52.

Phillips, John. 2000. "Two Theories of Fictional Names." American Philosophical Quarterly 37.2: 107-119.

Priest, Graham. 2005. Towards Non-being: The Logic and Metaphysics of Intentionality. Oxford: Oxford University Press.

Quine, Willard van Orman. 1948. “On What There Is.” Review of Metaphysics 2: 21-36.

—. 1962 Methods of Logic. London: Routledge.

Rapaport, William J. 1978. "Meinongian Theories and a Russellian Paradox." Nous 12.2: 153-180.

Remier, Marga. 2001. “A 'Meinongian' Solution to a Millian Problem.” American Philosophical Quarterly 38.3: 233-248.

Routley, Richard. 1979. Exploring Meinong's Jungle and Beyond. Departmental Monograph.

Russell, Bertrand. 1903. The Principles of Mathematics. Cambridge: Cambridge University Press.

—. 1905. "On Denoting." Mind 14: 479-493. 
-. 1918-1919. "Lectures on the Philosophy of Logical Atomism." Monist 28 (1918): 495-524; 29 (1919): 32-64, 190-222, 345-80. Reprinted in R.C. Marsh (ed.) (1956), Bertrand Russell: Logic and Knowledge. Essays 1902-1950. London: George Allen and Unwin: 177-281.

—. 1919. Introduction to Mathematical Philosophy. Routledge.

Sainsbury, R. M. 2010. Fiction and Fictionalism. London: Routledge.

Salmon, Nathan. 1998. "Nonexistence.” Noûs 32.3: 277-319.

-. 2014. "What is Existence." Empty Representations. Edited by Manuel GarciaCarpintero and Marti Genoveva. Oxford: Oxford University Press: 245-260.

Searle, John. 1979. Expression and Meaning: Studies in the Theory of Speech Acts. Cambridge: Cambridge University Press.

Strawson, P.F. 1950. “On Referring.” Mind 59: 269-86.

Thomasson, Amie. 1999. Fiction and Metaphysics. Cambridge: Cambridge University Press.

—. 2003. "Speaking of Fictional Characters". Dialectica 57.2: 207-26.

van Inwagen, Peter. 1977. "Creatures of Fiction." Philosophy and Literature 7: 67-77.

von Solodkoff, Tatjana. 2014. "Fictional Realism and Negative Existentials." Empty Representations. Edited by Manuel Garcia-Carpintero and Marti Genoveva. Oxford: Oxford University Press: 333-352.

Voltolini, Alberto. 2006. How Ficta Follow Fiction: A Syncretistic Account of Fictional Entities. Dordrecht: Springer.

Walton, Kenneth. 1990. Mimesis as Make-Believe: On the Foundation of the Representational Arts. Cambridge, Massachusetts: Harvard University Press.

Zalta, Edward. 1983. Abstract Objects: An Introduction to Axiomatic Metaphysics. Dordrecht: Reidel Publishing Company.

—. 1988. Intentional Logic and the Metaphysics of Intentionality. Cambridge, Massachusetts: The MIT Press.

—. 2003. "Referring to Fictional Characters." Dialectica 57: 243-54. 